\title{
$\begin{array}{ll}\text { Research Square } & \text { Preprints are preliminary reports that have not undergone peer review. } \\ \text { They should not be considered conclusive, used to inform clinical practice, }\end{array}$
}

\section{How does Governance Impact Malnutrition ? A Close Look at Factors Associated with Underweight in Children Under 5 Years in Ghana}

George Graves Woode ( $\sim$ george.woode@uni-hohenheim.de )

University of Hohenheim: Universitat Hohenheim https://orcid.org/0000-0002-3554-1443

\section{Regina Birner}

University of Hohenheim: Universitat Hohenheim

Research article

Keywords: malnutrition , underweight, children , Undernutrition

Posted Date: September 13th, 2021

DOI: https://doi.org/10.21203/rs.3.rs-861363/v1

License: (9) (1) This work is licensed under a Creative Commons Attribution 4.0 International License. Read Full License 


\section{Abstract}

Undernutrition remains a barrier to achieving the sustainable development goals in most developing countries. The United Nations identified that, the right mix of policies and actions that addresses the numerous, interrelated causes of hunger and undernutrition will be able to achieve Zero Hunger thereby ending hunger and undernutrition. In Ghana, $11 \%$ of all children under the age of 5years are underweight. Nutrition programs are traditionally funded through the government of Ghana budgetary allocations, to pay salaries and for the supply of logistics, and training. The objective of the study was to evaluate the effect of human resource capacity and budgetary expenditure on nutrition program outcomes for children under five years using in-depth interviews, anthropometric data on age and weight and data on nutrition human resource and expenditure in three regions from 2014 to 2017 in Ghana. The paper finds using linear mixed effects modeling that human and financial resources are not significant predictors of underweight besides, there are externalities in the implementation of nutrition programs for children under 5years due to poor targeting and information asymmetries, resulting in excludability in consumption of nutrition services, therefore nutrition programs may not be well-coordinated, and implemented pointing to government failure. Mother support groups contributed in reducing undernutrition in children under 5years through the cultivation and consumption of nutrition-sensitive agriculture value chain products .

\section{Introduction}

Undernutrition remains a barrier to achieving the sustainable development goals in most developing countries. To realize the totality of the 2030 Agenda for Sustainable Development, the United Nations identified that, the right mix of policies and actions from governments, civil society, and the private sector that addresses the numerous, interrelated causes of hunger and undernutrition will be able to achieve Zero Hunger thereby ending hunger and undernutrition (Swaminathan, 2014) It is estimated by the World Bank that around US\$10.3 billion is needed annually for funding of nutrition activities globally thus rendering the current disbursements levels by the international community, national governments and non-governmental organizations woefully inadequate(Susan Horton et. al. 2010 as cited in IFPRI, 2015).

Among the main factors that impact the implementation of disease prevention and health promotion programs in children are the human and financial resource available (Thomas, 2014). Applying too little resources in a health and nutrition program will not be able to protect the health and nutrition of the target group and be able to expedite the management of sickness. Ensuring the right number and mix of human resource needed for service provision is most likely to impact positively on organizational commitment and ultimately, on quality of care which is critical for advancing the quality of service provision, however realizing this objective remains a challenge (Pereira, Greenfield, Ranmuthugala, \& Braithwaite, 2013). Programing for nutrition should focus on strengthening the knowledge and skills of health workers as well as advocacy for funds to support scale-up of the programs (World et al., 2015). To this end, increasing the number of resources for a program (resources per person) will be imperative in achieving desired results(Newson et al., 2013) while maintaining the right balance between human resources, finances and consumables (drugs, and equipment), the main health system inputs, to ensure success (Adano, O’Neil, Browne, \& Fox, 2012).

According to World Health Organization report, the level of one's education influences the affinity to look for better opportunities which invariably causes health professionals to leave their less endowed or developed areas to where there are better opportunities especially from rural to urban areas and this results in the inadequate number and mix of certain categories of health professionals in one area and an excess in other areas. This puts a heavier workload on the already overstretched staff in the rural areas (WHO, 2016).

It is also a well-known fact the world over that the absence of enough skilled and well-resourced workforce is a major obstacle in achieving improved nutrition and child survival. Workers at the peripheral levels are the mainstay of any population-based intervention due to their outreach activities in communities cut off form static health facilities. More investment is therefore needed to boost the capacity and numbers of these category of frontline staff who are at the forefront in the fight against undernutrition for a successful nutrition program implementation (Mucha \& Tharaney, 2013).

A consequence of building the knowledge, and skills of the professional as well as the motivation of those individuals responsible for delivering nutrition services is the implementation of nutrition-sensitive activities as part of health programs. The amount of money available for implementation will determine the quality of personnel to hire as well as the ability to retain the best staff and

Page $2 / 27$ 
sustain effective practitioners. Therefore to provide high-quality care for clients the human resource available needs to be managed properly which calls for the implementation of strategies that will yield better results (World Health Organization, 2017).

At the heart of successful nutrition programs are community workers, their wages and inducements required for their motivation apart from their training and supervision. To realize widespread effects and better results adequate resources must be spent on each child (Crigler, Gergen, \& Perry, 2013).

Evidence from developing countries suggests that social support from government and NGOs in the form of conditional cash transfers for accessing nutrition services coupled with appropriate human and financial resources have increased uptake of nutrition services (Dupas, 2018). Inadequate staff, overstretched resource and time was often cited as a challenge in nutrition program implementation in Bangladesh as government health workers usually had to serve more people than had been estimated coming from a large catchment area in remote locations and often with very limited means of transport that had to be shared between competing activities. Equally worrying was the challenge of absenteeism among doctors and other high-end service providers who often are not available on all working days and even went home early although they got to work late. (Rose, Mostafa, \& Robbins, 2014).

Examples from Ethiopia also suggest that nutrition programs because of their target audience relied more on female health workers than their male counterparts. High Staff turnover through marriages transfer and pregnancies of these health workers increased workload in the process and presented significant challenges to program operations. an insufficient material resource such as vehicles and motorbikes were among key challenges impeding nutrition program implementation coupled with that, were other systemic factors such as inadequate funding or the late release of the budget. To address this human resource constraint more of the male health workers, had to be recruited while the adequate provision of logistical support especially for routine functions and timely release of funds became important to guarantee reliable program implementation(Warren \& Frongillo, 2016)

For 20 years, Senegal reduced significantly the prevalence of stunting from 33-19\%. However, the lack of an adequate budget for nutrition made it difficult to employ and sustain nutrition staff as well as sustain nutrition outreach programs in the communities (Kampman, Zongrone, Rawat, \& Becquey, 2016)

Despite the human resource constraint in implementing nutrition programs, there is also a lack of motivation for actors working in nutrition to collaborate. Once funding for nutrition programs are transparent and properly matched for the activities and ownership is strong especially at the implementation stage, it is likely that an improvement in nutrition governance will be observed (International Food Policy Research Institute (IFPRI), 2015)

According to Thrall,2018, there are externalities in the management of resource, as well as poor targeting leading to information asymmetries and excludability in consumption in market transactions resulting in poorly coordinated programs, with weak implementation that is disposed to rent-seeking and corruption which is a cause of government failure(Thrall, 2018)

A source of government failure as far as implementing nutrition program is concerned is the under provision of services as a result of failure to spend assigned funds due to government bureaucracies and lack of capacity to absorb and utilize these funds(Savage, 2013)(Zureiqat \& Shama, 2015). Therefore a key governance challenge is the management of funds allocated for program implementation especially in the implementation of social safety net programs(Zureiqat \& Shama, 2015) .

The capacity to track expenditures used to implement nutrition activities is important to better account for nutrition actions and it starts with an appreciation of budget allocated for nutrition specific activities. However, more often than not such budgetary analyses do not include recurrent expenditure such as staff costs (Picanyol, 2014).

\subsection{The Problem}

In Ghana $11 \%$ of all children under the age of $5 y e a r s$ are underweight. The worst incidence of malnutrition among children under $5 y e a r s$ can be found In the Northern region where $20 \%$ of all children under age 5years are underweight according to GSS (2015), Glover-amengor et al. (2016). The highest rate of stunting can also be found in the Northern Region while it is lowest in Greater Accra region (UNICEF 2019)This is followed by Central regions with $13.9 \%$ underweight among children under age 5years (Ghana Statistical Service, 2015) Greater Accra region has relatively better indices for malnutrition with $8.7 \%$ of children under age 5 who 
are underweight (Ghana Statistical Service, 2015),however factors that would account for the relatively better indices are not well documented. It is also the second most populous region and the capital city of Ghana being densely populated with populations spread in more urban than rural areas (ISD, 2017).. The Central region has the fastest growing population in Ghana followed by the populations of Greater Accra and Northern regions (Cudjoe, Azure, Assem, \& Nortey, 2013). Ghana's population is estimated at 29.4 in 2018 (UN, 2017)

Among the determinants of under nutrition is the poor financial access to nutrition services delivered through the health system as well as inadequate human capacity and governance for handling and delivering nutrition services. (Government of Ghana, 2013)

The relevance of the study again stems from the concerns of making the best use of existing human and financial resources in terms of its efficiency as well as the fiscal liability for program implementation and the need to make appropriate decisions to resolve problems of implementation based on how nutrition service indicators are impacted through the implementation of nutrition programs (Ministry of Health [Ethiopia], 2014)

Studies that identify governance challenges and their effect in the implementation of nutrition programs in Ghana are hard to come by. The governance issues inherent in nutiriton program implementation provoked the researcher to explore the governance challenges of implementing nutrition programs from a budget and human resource stand point in Ghana. The study also evaluated the transmission effect of governance policies being implemented and was carried out using repeated cross-sectional data from 2014 to 2017 complemented by in-depth interviews with stakeholders in three purposively sampled regions in Ghana namely the Northern region; Central region and Greater Accra regions. It is expected that this research will contribute to academic learning and serve as a resource material for research purpose

\subsection{Objective of the study}

The study aimed to evaluate the effect of governance on nutrition program outcomes especially for children under five years with specific reference to the human resource capacity and budgetary expenditure used for service delivery in Ghana

\subsection{Research questions}

To realize this objective of evaluating the effect of governance on nutrition program outcomes the research questions will guide the study are as follows:

a. What are the quantitative outputs in relation to the inputs in program implementation?

b. How do health personnel and expenditure for service provision affect the achievement of nutrition program outcomes?

c. What are the positive and negative impacts of nutrition human resource and expenditure on nutrition indicators ?

\subsection{Structure of the paper}

The paper is divided into three sections. The first section will present the introduction and brief notes on the research methods and the limitations of the study. The second section presents the findings from the analysis of the effect of human resource and budget expenditure on nutrition outcomes for children under 5years in three selected regions as a case study. The concluding section discusses the findings and its effect on underweight for children under 5years. It then draws conclusions to guide the local governance architecture inorder to sidestep identified governance challenges

\subsection{Conceptual Framework}

This paper will adopt a conceptual framework based on the authors' own illustration. Figure 1Conceptural framework below depicts a conceptual framework that illustrates the relationship between nutrition programs that are implemented to address nutritionsensitive or nutrition-specific problems and the resultant governance challenges associated with the demand side and supply-side factors of nutrition program implementation, which themselves are caused by some fundamental governance challenges such as the lack of resources, both human and financial and information asymmetry. The framework represents the key foundations for analyzing the interrelationships between the government, the private sector NGOs and CBOs with the community or caregivers for that matter. Key areas supported by these foundation elements include inter-sectoral collaboration, decentralization, program management quality, workforce development and community engagement. This framework can be used to assist the systematic assessment of governance challenges and the evaluation of nutrition activity within public health and community nutrition

Page $4 / 27$ 
practices. Intersectoral collaboration, as well as decentralization, are important elements of any nutrition program where governance issues of budgeting and decision- making roles are transferred from central to local levels of government, (Britto et al., 2014).

Governance issues in nutrition programs happen during the development and delivery of public health programs therefore, nutrition programs need to be planned in parallel with other strategies. The assessment of governance challenges in programs would involve various stakeholders at different levels be it from the community side or the government and private sector side on resource availability and use. A wide range of settings are used to deliver nutrition program services which require good governance to ensure an efficient and effective program. Strategies that can be adopted to ensure program delivery can be home visits, clinic and/or community-based outreach programs as well as behavioural change communication strategies.

Nutrition programs could also be funded by government or non-governmental organizations and implementing it would require regulations and protocols to be put in place to ensure transparency which strengthens accountability and reduces transaction cost and is essential in ensuring that program benefits target population.

The dimensions of governance in public project implementation are the effectiveness of the government with respect to the resources such as human and financial that can be harnessed to achieve success in putting together and running government social programs (Brunet \& Aubry, 2016); Accountability by way of decentralization of programs as an avenue to make governments more accountable to the people they serve (OECD, 2014); the rule of law in a transparent environment which deals with formal and informal mechanism in place for economic activity to thrive, the creation and enforcement of laws and regulations and how organizations set up for this purpose go about carrying out their mandate. Transparency and information which mirrors societal values, culture and traditions which is essential in ensuring that planned program implementation benefit target populations(Johnston, 2016) will be applied to this framework to assess program coverage, service provision, the impact of the program and its efficiency to avoid the immediate and long term consequences of the causes of undernutrition for children under 5years. Strong ownership of program implementation is likely to yield improvements in nutrition governance for better nutrition outcomes.

From Fig. 1 conceptual framework below, child undernutrition stems primarily from nutrition-specific causes and nutrition-sensitive causes. These are complemented by community behavioral change. Nutrition programs to address child undernutrition are implemented by the government nutrition service providers, as well as the private sector organizations made up of private businesses, Non-governmental organization (NGO) and community-based organization (CBO) all from the supply side. On the demand side, the role of community social support groups, caregivers and community norms and informal laws impact child nutrition habits. The government faces governance challenges in their implementation of nutrition-specific and nutrition-sensitive programs where nutrition counselling and distribution of commodities are given to caregivers in such programs. Health workers also take advantage of the enabling environment to organize demonstration cooking for caregivers in the communities they serve taking advantage of community social support groups who act as change agents for the health providers. In the implementation of these activities, challenges encountered are fundamental challenges due to limited capacity in terms of human and financial resource as well as due to the large scale of the program being implemented. There is also the issue of alleged bribery and political interference in public procurement processes in the supply of items leading to substandard quality of items apart from the reduced quantities that will be available and these governance challenges are similar to what NGOs face in the provision of nutrition goods and services.

Community-based organizations (CBO) also face fundamental governance challenges of their own in the implementation of behavior change communication or social support strategies targeted at imparting nutritional status of children under $5 y e a r s$. The benefits accruing from social support groups may not be non-excludable in consumption such that other community people may benefit from nutrition counselling, lessons from demonstration cooking and other safety-net programs undertaken even though they do not attend the sessions thereby creating little incentive to belong to a social group within the community. Another governance challenged faced by CBOs is social exclusion and local elite capture, where perceived "rich" members of a social group get to benefit more at the expense of the poor members in the group. There could also be challenges by the composition of households as well as cultural practices within the community that often results in poor or wrong targeting of program beneficiaries. This leads to food insecurity,an intermediate governance challenges as a result of inadequate nutrition education and 
counselling and poor targeting resulting in a lack of dietry diversity for children under 5years. The main governance challenge encountered is the poor breastfeeding and complimentary feeding practice which ensures that the dietry intake of the children remains poor which makes them undernourished affecting their nutritional status,

\section{Materials And Methods}

\subsection{Study Sites Selection and criteria}

Table 1 Study Sites and their key attributes provides a summary of key attributes of the selected study sites. Within the period under review,the Northern Region, (Fig. 2 The Selected Regions of Ghana) in terms of land area was the largest region of Ghana with Tamale as its capital. The region is characterized by dry climate and has a single rainy season with about $750 \mathrm{~mm}$ to $1050 \mathrm{~mm}$ of rain from May to October. Agriculture, constitute the main economic activity (ISD, 2017). The Central Region (Fig. 2) lies within the dry equatorial zone and moist semi-equatorial zone. The annual average rainfall in the region is about 1,500mm with the peak of the rainy season from May-June and September-October while the period from December- February is characterized by dry season with a brief period of rains in August. (ISD, 2017).

The Greater Accra Region (Fig. 2) is the smallest region in Ghana in terms of land area, yet the second most populated region with a population of over 4 million people. The region falls within the dry coastal equatorial climatic zone and so has a relatively dry climate. Rainfall is heavier in the northern parts of the region than along the coast with June being the peak of the major rainy season, while October is the peak for the minor rainy season. The main farming season coincides with the main rainy season between April and July. (ISD, 2017).

Table 1

Study Sites and their key attributes

\begin{tabular}{|ll|}
\hline Region & Key attributes \\
has the highest under-5 mortality rates in Ghana & $\begin{array}{l}\text { Children in the region are more likely to be underweight than in other regions of Ghana with } 33 \% \text { stunting in children } \\
\text { under 5years } \\
\text { has the second highest under-5year mortality rates after Northern region }\end{array}$ \\
\hline Central & $\begin{array}{l}\text { Has one of the worst weight-for-age with mean Z-score below - } 2 \text { of the standard deviation. 25\% of children under } \\
\text { age } 5 \text { are stunted and waisted }\end{array}$ \\
\hline $\begin{array}{l}\text { Gutritional status of children under 5years in the region are among the best in the country } \\
\text { Accra }\end{array}$ & $\begin{array}{l}\text { much lower percentage of children under age } 5 \text { classified as malnourished according to anthropometric indicators } \\
\text { of height-for-age, weight-for-height, and weight- for-age as 19\% of children 0-59months are stunted and waisted }\end{array}$ \\
\hline Source: (GSS, 2011);(Ghana Statistical Service, 2015);(Ghana Statistical Service, 2019)
\end{tabular}

\subsubsection{Data Collection}

A four-year repeated cross-sectional data (2014-2017) comprising anthropometric measurements of weight and age of children under age 5years reached by nutrition programs as recorded during routine community and facility-based Growth Promotion activities in a total of 78 districts each year disaggregated as Northern $=29$ districts, Central $=22$ districts and Greater Accra $=27$ districts was sourced from the Ghana Health service nutrition and child health reports. Data for the nutrition and child health report is collated monthly from the child welfare clinic registers in each of the 2,692 health facilities in total located in the 78 districts in the three surveyed regions .Details of the child's weight, the age as well as other details of children under age 5 who were provided with nutrition and growth promotion services in the surveyed regions and districts are recorded in the child health form which is compiled into a report. The nutrition and child health reports are uploaded onto the online District Health Information Management Systems (DHIMS) where the data is available from the 25th day of every month for viewing or download for research, planning, and other management purposes. All children from 0-59 months who attended a child welfare clinic in a health facility in the 78 districts in the three regions over the four year period were part of the data pooled at one-month interval from January of the 
calendar year. This data was complemented by data taken on the human resource distribution from the Ghana Health Service, and financial disbursements for nutrition services sourced from United Nations Children Fund (UNICEF); the main development partner in the nutrition space in Ghana, for the three regions. In-depth interviews were held with Ghana Health Service Regional Nutrition officers of the sampled regions as well as with sampled community mother-to-mother support group members to know how nutrition-sensitive and nutrition-specific programs were implemented from the demand and supply sides and their role in the process as well as the challenges encountered during the implementation process and how they were overcome.

\subsection{Data Analysis}

The time series anthropometric data on weight and age sourced from the Ghana Health Service monthly nutrition and child health report was collated from each of the 78 districts in the three sampled regions and their Z-score means calculated to identify children who are underweight ( -2 Standard Deviation of the mean) using this formula:

$\mathbf{z}=\mathbf{X}-\boldsymbol{\mu} / \boldsymbol{\sigma}$, Where

$\mathbf{X}$ is the individual wt $; \boldsymbol{\mu}$ is the mean weight and $\boldsymbol{\sigma}$ is the standard deviation

Weight-for-age is an indicator that combines height-for-age and weight-for-height. It measures both acute and chronic malnutrition. According to the World Health Organization Multicenter Growth Reference study, as cited in the Ghana demographic and health survey, 2015, Children whose weight-for-age is below - 2 standard deviation (SD) from the median of the reference population are classified as underweight while children whose weight-for-age is below - 3 SD from the median are also said to be severely underweight (de Onis et al, 2006 as cited in GSS, 2015). The proportion of children less than 5 years of age registered in well-child clinics with global malnutrition (weight-for-age) less than 2 Standard Deviation below the standard mean was computed for each of the health facilities in 78 districts in three regions to get the prevalence of underweight(weight-for-age) by dividing the total children underweight by the total number of children weighed percent in the survey regions over the four years thereby establishing a trend in underweight in children under 5years for the study regions. This indicator measures the performance of child health programs. To better understand the variables accounting for the observed trend in reduction in the underweight, a linear mixedeffect model was used to predict the effect of human resource and expenditure for nutrition program implementation as covariates on nutrition program outcome (prevalence of underweight in children under 5 years ) using SPSS (Statistical package V21) .

The choice of using the Linear mixed effects (LME) model for this analysis stemmed from its strengths in handling correlated data and unequal variances especially in cases of repeated measurements of the experimental units as is the case with this data and this clearly differentiates the mixed effect models from the General Linear Models GLM. It also has an advantage over linear regression models for data that are collected and summarized in groups.LME can also handles more complex situations in which experimental units are nested in a hierarchy, for example, a sample of children under age 5years attending child welfare clinics selected from a sample of static or outreach clinics in a district as is the case with the data used for this study.

In the general model $\mathbf{y}=\mathbf{X} \boldsymbol{\beta}+\mathbf{Z u}+\boldsymbol{\varepsilon}$

Where $\mathbf{y}$ is the outcome/dependent variable (percent underweight) ; $\mathbf{X}$ is the predictor variables - nutrition human resource and expenditure; $\boldsymbol{\beta}$ is a vector of the fixed-effects regression coefficients (the $\beta \mathrm{s}$ ); $\mathbf{Z}$ is the random effects (the random complement to the fixed $\mathbf{X}$ ); $\mathbf{u}$ is a vector of the random effects (the random complement to the fixed $\beta$ ); and $\boldsymbol{\varepsilon}$ is the error term, a vector of the residuals, that part of $\mathbf{y}$, the outcome variable that is not explained by the model, $X \beta+Z u(C o s t e r, 2014)$

In using this model our objective is to test if nutrition human resource and budgeted expenditure for nutrition programs in all the 78 districts in three sampled regions over a 4-year period is an important predictor of percent underweight in children under $5 y e a r s$. Total nutrition human resource and budget expenditure for nutrition computed for the sample is therefore used as fixed effect factors for the model. We also use human resource and budget expenditure as random effect to correct for possible sampling difference due to variation in human resource capacities in order to identify all different human resource capacities in the different categories. It also adjusts for the variation in these factors due to different expenditures for nutrition programs. Percent underweight in all districts in the three regions are followed for four years. The region and year are also used as fixed effect to adjust for possible trends during this period. We also model the possibility of correlation of the residual errors within each child under 5 years in the sample. 
Given the adopted model:

$y_{i}=\beta_{0}+\beta_{1} \chi_{i 1}+\beta_{2} \chi_{i 2}+\varepsilon_{i} i=1 \ldots . . n$

$\boldsymbol{\beta}_{0}$ - is the intercept which is the mean percent underweight per child under age 5 per year by a region with no expenditure on nutrition programs or no human resource for nutrition services.

$\boldsymbol{\beta}_{1}$ - is the change in underweight given a $1 \%$ change in total nutrition human resource

$\boldsymbol{\beta}_{2}$ - is the change in underweight given a $1 \%$ change in expenditure for nutrition

$\boldsymbol{\varepsilon}$ - the error term or the unobservable or unimportant errors of measurement in the data; approximation due to linear function; and random behaviour that may be present in each individual.

The number of children reached by nutrition programs is recorded in the Child Welfare Clinic (CWC) registers and aggregated onto the Monthly Nutrition and Child Health report form. To be part of the numerator a child was counted as having been reached by nutrition programs if $s$ /he receives one or more of the following nutrition-specific interventions directly or through the mother/caretaker: (Table 2: Nutriton Specific Intervention offered during Child Welfare Clinics ).

Table 2

Nutriton Specific Intervention offered during Child Welfare Clinics

\section{Behavior change communication interventions that promote essential infant and young child feeding behaviors including:}

- Immediate, exclusive, and continued breastfeeding, - Appropriate, adequate and safe complementary foods from 6 to 24 months

2 Vitamin A supplementation in the past 6 months

3 Zinc supplementation during episode of diarrhea

4 Multiple Micronutrient Powder (MNP) supplementation

5 Treatment of severe acute malnutrition

6 Treatment of moderate acute malnutrition

7 Growth monitoring and promotion

8 Direct food assistance (rations, food vouchers)

Source: Ghana Health Service Standard Opeation Procedure 2018 (unpublished)

The denominator is the population of children under age 5years in each facility of the 78 districts In the three regions. Again Child Welfare Clinic (CWC) coverage, therefore, represent the percentage of children 0-59 months who receive one or more nutritionspecific interventions in the targeted population.

\subsection{Limitations of the Study}

The quantitative data used in this study was derived solely from children age 0 to 59 months of age registered in well-child clinics. Therefore, only children who attended routine health service nutrition programs were captured as the surveyed population. It is plausible that conditions of such children could be better than children within the community who are undernourished but do not attend child welfare clinics and also not reached by any nutrition program. Data from children seen at health facilities only, may not provide a consistent assessment of the nutritional status as a representative sample of the population would give during a survey. It was also not possible to obtain financial data on expenditure for nutrition programs from actors in the nutrition space in Ghana because as Picanyol 2014 asserted nutrition programs were often combined with mainstream health delivery, therefore, it was very difficult to divorce nutrition-specific expenditures from the aggregated expenditure without making assumptions which may partly explain the difficulty in getting such information from non-governmental stakeholders. Financial data on actual disbursements for nutrition programs that were obtained from a major development partner in nutrition interventions in Ghana,United Nations Children Fund (UNICEF) Ghana office, was used as a proxy to capture expenditure for nutrition program implementation in Ghana. The study 
did not also control for the effects of the level-of-effort of the human resource for nutrition, instead the proportion of children reached with nutrition programs per region was used as a proxy indicator to gauge the level-of-effort put in by the health workers. Again, due to data limitations to the researcher, other socio-economic indicators that could potentially change from year to year and therefore impact on the results could not be used apart from government human resource deployment for nutrition programs and expenditure for nutrition services.

\section{Results}

The second section presents the findings from the analysis of the effect of human resource and budget expenditure on nutrition outcomes for children under 5years in three selected regions as a case study

\subsection{What are the quantitative outputs in relation to the inputs in nutrition program implementation?}

Nutrition interventions are carried out typically at the static health facilities and during community outreach programs. During the first seven days of postnatal care the midwife is responsible for supervising the welfare of the newborn by reinforcing breast feeding education provided during antenatal care and provide the mothers, advice on dietary requirements when she visits the newborn at home or during routine postnatal care at the facility. When the midwife ceases to visit the newborn after the seventh day, the professional nurse takes over supervising the welfare of the baby until the child is five years old. The professional nurse discharges this duty by supervising weighing at Child Welfare Centers and providing advice to mothers on their baby's diet and on choices of weaning foods and other requirement for the healthy development of the child including recognizing signs of disease and prompt reporting to clinic for treatment. The Community Health nurses who man health facilities at the peripheral level known as Community Health Planning and Services (CHPS) compounds are trained to carry out outreach nutrition interventions such as vitamin A supplementation; food based strategy for micronutrients; community based promotion of breast feeding ; maternal nutrition and complementary feeding; community based growth promotion including nutritional status assessment and also promoting the essential nutrition actions at the community level. While they embark on their routine outreach programs in the communities, another category of nurses, the Enrolled nurses who are also stationed at the CHPS compound stay in the facility to provide curative services including nutrition related disease conditions and nutritional rehabilitation to mother and baby who call at the facility. Nutrition officers are core members of the district health management teams and play a supervisory role for all nutrition related interventions and serve as master trainers building the capacity of the district staff and community health workers in nutrition program interventions.

In total, enrolled nurses make up the highest number of staff cadre in the three regions over the four-year period while Nutrition Officers were the least staff cadre over the same period as depicted in Table 3: Nutrition Human Resource distribution by Cadre (2014-2017). The period 2014-2017 saw a reduction in the numbers of all the listed staff cadre of between $43 \%$ (for midwifes) to $81 \%$ (for nutrition officers) involved in nutrition program implementation in Greater Accra region, however the same cannot be said for the Northern region where the health worker categories involved with nutrition programs such as nutrition officers, midwifes, Professional nurses and Community Health Nurses had consistently increased ( refer to Table 3: Nutrition Human Resource distribution by Cadre (2014-2017)) 
Table 3

Nutrition Human Resource distribution by Cadre (2014-2017)

\begin{tabular}{|c|c|c|c|c|c|}
\hline & $\begin{array}{l}\text { Total Enrolled } \\
\text { Nurses }\end{array}$ & $\begin{array}{l}\text { Total Nutrition } \\
\text { Officers }\end{array}$ & $\begin{array}{l}\text { Total } \\
\text { midwifes }\end{array}$ & $\begin{array}{l}\text { Total Professional } \\
\text { Nurses }\end{array}$ & $\begin{array}{l}\text { Total Community Health } \\
\text { Nurses }\end{array}$ \\
\hline Central & 9217 & 40 & 3400 & 6868 & 8155 \\
\hline 2014 & 2251 & 8 & 718 & 1464 & 2045 \\
\hline 2015 & 1684 & 9 & 536 & 1265 & 1568 \\
\hline 2016 & 2495 & 17 & 1018 & 2147 & 2455 \\
\hline 2017 & 2787 & 6 & 1128 & 1992 & 2087 \\
\hline $\begin{array}{l}\text { Greater } \\
\text { Accra }\end{array}$ & 10357 & 119 & 5980 & 11469 & 11471 \\
\hline 2014 & 4095 & 75 & 2081 & 4684 & 4971 \\
\hline 2015 & 2323 & 10 & 1390 & 2749 & 2243 \\
\hline 2016 & 2057 & 20 & 1316 & 2023 & 2293 \\
\hline 2017 & 1882 & 14 & 1193 & 2013 & 1964 \\
\hline Northern & 3128 & 19 & 462 & 924 & 939 \\
\hline 2014 & 130 & 2 & 11 & 15 & 63 \\
\hline 2015 & 1003 & 1 & 95 & 253 & 262 \\
\hline 2016 & 921 & 10 & 147 & 304 & 275 \\
\hline 2017 & 1074 & 6 & 209 & 352 & 339 \\
\hline $\begin{array}{l}\text { Grand } \\
\text { Total }\end{array}$ & 22702 & 178 & 9842 & 19261 & 20565 \\
\hline
\end{tabular}

Apart from the traditional universities that offer degree programs in nursing and nutrition, there are 27 public nursing training institutions with 6 of them training solely Community Health Nurses while the remaining train all category of nurses (community health nurse, midwifes Professional nurse, enrolled nurse) just one institution trains nutrition officers. There are also a few private nursing training institutions dotted around the country that partner government in training health workers. Enrolled nursing and community Health nursing are at the lower end of the nursing profession in terms of certificate awarded and length of training therefore entry requirements are lower than what is demanded for entry to professional nursing or midwifery. Because of that, the intake for community health and enrolled nursing training is much higher therefore large numbers of these categories of nurses are graduated by the training institutions at shorter intervals than the other cadres and this explains their large numbers than the midwifes, nutrition officers and professional nurses.

Over the 4year period from 2014 to 2017, almost seven and a half million United States Dollars (USD) (USD 7,413,245.79) was spent implementing nutrition programs in the three regions altogether. It is evident from (Fig. 3 Estimated expenditure on nutrition programs in the three regions ,2014-2017) that most of the resources which are equivalent to about $60 \%($ USD $4,384,287.00)$ of the total expenditure for nutrition programs was in the Northern region, while another $25 \%(U S D 1,890,586.26)$ of the expenditure was in the Central region leaving the remaining $15 \%$ as expenses made in implementing nutrition programs in the Greater Accra region.

\subsection{How does health personnel and expenditure for service provision affect the achievement of nutrition program outcomes?}

The total resources expended on nutrition programs annually for the three regions grew by a little over 40\% (43\%) from 2014 to 2016 but fell by 50\% from 2016 to 2017 from Fig. 4 : Trends in Total Expenditure for Nutrition program in all three regions (20142017). which affects program funds including nutrition programs that are largely donor-driven. 
Despite the inherent differences in the expenditure for nutrition program implementation, the proportion of children under $5 y e a r s$ who are underweight in the three regions has seen a consistent improvement between 2014 to 2017 as depicted in Fig. 5 : Children Underweight as an Outcome of Nutrition Program Implementation (2014-2017). although the quantum of reduction in underweight differed from one region to the other, which could partly be attributed to the level of effort in the implementation mix of nutrition programs in the three regions.

The Northern region achieved an $81 \%$ reduction in underweight of children under age 5 from $19.86-3.69 \%$ (95\% Cl: $-1.20 \%-21.25 \%)$ representing the highest reduction in underweight over the period (2014-2017). Central region obtained a $59 \%$ reduction in underweight from 11.13-4.6\% (95\% Cl: 2.89\%-11.98\%) while Greater Accra had the lowest reduction (49\%) of underweight from $7.21-3.71 \%$ (95\% Cl: $2.81 \%-7.61 \%$ ) over the same period. This indicator measured the performance of child health programs.

From Fig. 6 : Human Resource for Nutrition programs and Average underweight in All Regions (2014-2017), putting the nutrition staff cadre for the three regions together, there is an overall reduction of $25 \%(24.6 \%)$ in nutrition staff over the four years. However, the proportion of children less than 5years who were underweight also declined. A disaggregation by staff cadre for each of the region as earlier shown in Table 1 above shows a steady reduction in nutrition-related staff in Greater Accra while that of Northern and even Central region has increased over the 4 years.

One plausible reason for the observed trend could be the usual administrative reposting from the Greater Accra region to other regions, while some of them may also have proceeded on study leave or retired from active service. But despite that, the Greater Accra region still maintains the highest number of all cadre of staff and this could be due partly to the affinity to stay and work in urban areas as opposed to rural areas where amenities are scarce. Northern region in absolute numbers has the lowest number of cadres for nutrition compared with the numbers in the two other regions but notwithstanding, the staff cadre for nutrition program implementation increased by almost $800 \%$ from 2014-2017 in the region. This could be a response to the several nutrition interventions being implemented by several development partners in the region as well as the geographic size of the region being the larger administrative region in Ghana compared to the two other regions. This is also agrees with the move by the government to allocate newly trained health workers to regions based on critical staff need.

The government also instituted incentive packages such as allocation of motorbikes to staff working in hard-to-reach areas, faster promotions and job progression, study leave packages as well as financial incentives meant to encourage especially midwives and community health nurses to be posted to rural areas and peripheral health facilities $(\mathrm{MOH}, 2015)$. The government strategy, therefore, to improve the availability of trained staff for child health and nutrition may have achieved some success in the northern region and to a greater extent in the Central and Greater Accra regions.

When all the values were plugged into the model, the results of the linear mixed effect model produced a "Type III Tests of Fixed Effects" Table 4 Type III Tests of Fixed Effects Both total nutrition human resource "HRTOT" and expenditure on nutrition services "AMTSPENT" are not significant at the .05 level while the years reviewed "YEAR" was significant at the .05 level. This means that human resource and expenditure for nutrition services are not potentially important predictors of the dependent variable (underweight) however the percent of underweight in children under 5years reduced over the four-year period. The "Estimates of Fixed Effects" table Table 5 Estimates of Fixed Effects gives estimates of individual parameters, as well as their standard errors and confidence intervals. From Table 3, the effect of expenditure for nutrition services (AMTSPENT) on the percent underweight is larger than that for human resource capacity (HRTOT) although both are not significant. 
Table 4

Type III Tests of Fixed Effects

\begin{tabular}{|lllll|}
\hline a & & & & \\
\hline Source & Numerator df & Denominator df & F & Sig. \\
\hline Intercept & 1 & 152.040 & 46.701 & .000 \\
\hline AMTSPENT & 1 & 72.014 & .926 & .339 \\
\hline HRTOT & 1 & 150.708 & .004 & .947 \\
\hline Region & 2 & 89.557 & .871 & .422 \\
\hline YEAR & 3 & 106.514 & 17.215 & .000 \\
\hline a. Dependent Variable: \% underweight. & & \\
\hline
\end{tabular}

Table 5

Estimates of Fixed Effects

\begin{tabular}{|c|c|c|c|c|c|c|c|}
\hline \multirow[t]{2}{*}{ Parameter } & \multirow[t]{2}{*}{ Estimate } & \multirow[t]{2}{*}{ Std. Error } & \multirow[t]{2}{*}{ df } & \multirow[t]{2}{*}{$\mathrm{t}$} & \multirow[t]{2}{*}{ Sig. } & \multicolumn{2}{|c|}{ 95\% Confidence Interval } \\
\hline & & & & & & Lower Bound & Upper Bound \\
\hline Intercept & 3.710933 & .700173 & 118.610 & 5.300 & .000 & 2.324475 & 5.097391 \\
\hline AMTSPENT & .026670 & .027715 & 72.014 & .962 & .339 & -.028578 & .081918 \\
\hline HRTOT & -.008334 & .125630 & 150.708 & -.066 & .947 & -.256558 & .239890 \\
\hline [Region = 1] & 1.021657 & .928097 & 55.410 & 1.101 & .276 & -.837981 & 2.881296 \\
\hline [Region = 2] & -.265441 & .866776 & 87.559 & -.306 & .760 & -1.988098 & 1.457216 \\
\hline [Region = 3] & $0^{\mathrm{b}}$ & 0 & . & & . & . & . \\
\hline [YEAR = 1] & 5.771402 & .850038 & 120.866 & 6.790 & .000 & 4.088509 & 7.454294 \\
\hline [YEAR = 2] & 2.669876 & .767891 & 161.881 & 3.477 & .001 & 1.153500 & 4.186251 \\
\hline [YEAR = 3] & .929314 & .543169 & 104.915 & 1.711 & .090 & -.147701 & 2.006329 \\
\hline [YEAR = 4] & $0^{\mathrm{b}}$ & 0 & . & . & . & . & . \\
\hline \multicolumn{8}{|c|}{ a. Dependent Variable: \% underweight. } \\
\hline \multicolumn{8}{|c|}{ b. This parameter is set to zero because it is redundant. } \\
\hline
\end{tabular}


Table 6

Estimates of Covariance Parameters ${ }^{a}$

\begin{tabular}{|c|c|c|c|c|c|c|c|}
\hline \multirow[t]{2}{*}{ Parameter } & & \multirow[t]{2}{*}{ Estimate } & \multirow[t]{2}{*}{ Std. Error } & \multirow{2}{*}{$\begin{array}{l}\text { Wald } \\
Z\end{array}$} & \multirow[t]{2}{*}{ Sig. } & \multicolumn{2}{|c|}{ 95\% Confidence Interval } \\
\hline & & & & & & $\begin{array}{l}\text { Lower } \\
\text { Bound }\end{array}$ & $\begin{array}{l}\text { Upper } \\
\text { Bound }\end{array}$ \\
\hline \multirow[t]{13}{*}{$\begin{array}{l}\text { Repeated } \\
\text { Measures }\end{array}$} & $\begin{array}{l}\text { Var: }[\text { Region }=1] *[\text { YEAR }= \\
\text { 1] }\end{array}$ & 81.685163 & 22.588878 & 3.616 & .000 & 47.506760 & 140.452975 \\
\hline & $\begin{array}{l}\text { Var: }[\text { Region }=1] *[\text { YEAR }= \\
\text { 2] }\end{array}$ & 45.906539 & 12.033234 & 3.815 & .000 & 27.463361 & 76.735342 \\
\hline & $\begin{array}{l}\text { Var: }[\text { Region }=1] *[\text { YEAR }= \\
\text { 3] }\end{array}$ & 21.083749 & 5.409674 & 3.897 & .000 & 12.751060 & 34.861765 \\
\hline & $\begin{array}{l}\text { Var: }[\text { Region }=1] *[\text { YEAR }= \\
4]\end{array}$ & 15.074520 & 4.192371 & 3.596 & .000 & 8.740093 & 25.999856 \\
\hline & $\begin{array}{l}\text { Var: }[\text { Region }=2] *[\text { YEAR }= \\
\text { 1] }\end{array}$ & 27.933385 & 8.941682 & 3.124 & .002 & 14.915839 & 52.311773 \\
\hline & $\begin{array}{l}\text { Var: }[\text { Region }=2] *[\text { YEAR }= \\
\text { 2] }\end{array}$ & 17.034787 & 5.118128 & 3.328 & .001 & 9.453484 & 30.695982 \\
\hline & $\begin{array}{l}\text { Var: }[\text { Region }=2]^{*}[\text { YEAR }= \\
\text { 3] }\end{array}$ & 10.262663 & 2.500235 & 4.105 & .000 & 6.366292 & 16.543734 \\
\hline & $\begin{array}{l}\text { Var: }[\text { Region }=2] *[\text { YEAR }= \\
4]\end{array}$ & 8.815132 & 2.242591 & 3.931 & .000 & 5.354034 & 14.513646 \\
\hline & $\begin{array}{l}\text { Var: }[\text { Region }=3]^{*}[\text { YEAR }= \\
\text { 1] }\end{array}$ & 46.452801 & 12.689342 & 3.661 & .000 & 27.195202 & 79.347185 \\
\hline & $\begin{array}{l}\text { Var: }[\text { Region }=3]^{\star}[\text { YEAR }= \\
\text { 2] }\end{array}$ & 59.099730 & 16.180066 & 3.653 & .000 & 34.557893 & 101.070343 \\
\hline & $\begin{array}{l}\text { Var: }[\text { Region }=3] *[\text { YEAR }= \\
\text { 3] }\end{array}$ & 26.309951 & 7.486335 & 3.514 & .000 & 15.063152 & 45.954094 \\
\hline & $\begin{array}{l}\text { Var: }[\text { Region }=3] *[\text { YEAR }= \\
4]\end{array}$ & 4.685435 & 1.240289 & 3.778 & .000 & 2.788861 & 7.871780 \\
\hline & 694228 & .048288 & 14.377 & .000 & .587199 & .777399 & \\
\hline
\end{tabular}

The results suggest that there are other assoiated factors that contributed to the reduction in underweight .

According to this survey data, the community health nurses and regional nutrition officers from the three regions, during Ante Natal Care (ANC) visits and during Postnatal care (PNC) visits, provide nutrition education to mothers including promotion of exclusive breast feeding for the neonates, maternal nutrition and complementary feeding after weaning among other interventions. The health workers, during ANC and PNC, facilitate the formation of support groups known as the mother-to-mother support groups taking advantage of members of already existing social support groups within the community. The mother support groups are composed of small groups of 3 up to about 15 mothers in each group, of any age, with a common interest of learning about and discussing issues of infant and young child nutrition.

According to the survey data from regional nutrition officers in the three regions, mother to mother support groups are active mostly in rural communities where social bonding is stronger than in urban communities. The challenge encountered in the Greater Accra and the Central regions with the organization of the mother to mother support group is that, there are more urban communities than rural which does not encourage the proper functioning of these support groups. Again, members of these mother support groups 
rather than work as volunteers knowing that this support groups are founded on the values of volunteerism, began to demand for incentives and payments in return for their services as nutrition change agents which can not be sustained.

The data suggest that In the Greater Accra region mother to mother support groups are usually formed out of existing women's groups such as police women's association, Muslim women's association and other like groups. The activities of the mother support groups are then integrated into the women's groups however in many instances, the objective of these women's associations differed from that of the mother's support group making it difficult to sustain the mother's groups within these associations. The mother to mother support groups are therefore active in few communities in the region. same reasons hold for the relative inactivity of the mother support groups in the Central region.

According to the survey data derived thorugh interviews with Ghana Health Service regional nutrition officers, in the urban areas, it is also more difficult to send information to all residents in a locality espercially poor urban communities, about the holding of outreach child welfare clinics due to logistical constrainsts and lack of consultation in the planning of such activities. Therefore, parents in such areas commonly complained of the lack of awareness about the holding of such outreach activities which impacted uptake of services among urban dwellers in general.

The poor targeting of under 5year old children in urban areas effectively ensures that mostly children in rural communities formed part of the children whose nutritional status are assessed and would largely accounts for the trend in underweight of children under 5years in the central and the Greater Accra regions. The incidence of poor targeting for nutrition services suggest that there could be a potentially large cohort of children under age 5 with poor nutritional status among the population in mostly poor urban communities who have been missed.

Survey data from interviews with the regional nutrition officer in the Northern region of Ghana suggest that mother to mother support groups are very active in most communities in every district in the region. members of mother support groups are the mouth piece of the community health nurses in the communities and they act as change agents with respect to maternal and child nutrition education, sharing their experiences in breastfeeding and complementary feeding practices among themselves in the community. The mother support groups also run small loans and saving schemes within the group and assist each other with small loans to meet their basic needs including hiring additional hands in clearing communal farm lands in preparation for planting during the farming seasons or for ploughing their lands. The successes of this support group in the region had led to the formation of so called father to farther support groups in communities in 17 of the 25 districts in the region to teach maternal and child nutrition to fathers who are usually household heads and decision makers in the home to obtain their buy-in as far as nutrition and health needs of children under 5years and mothers is concerned.

The community health nurses work closely with these groups in the areas of nutrition education to mothers where nutrition counselling is tailored to the consumption of nutrition sensitive agriculture nutrient-rich value chain products. The mother-to-mother support groups in the northern region commonly provide communal labor to their members to plough small fields in the communities for planting of leguminous crops high in protein such as soybeans and vitamin A rich Orange-Fleshed Sweet Potatoes to support the consumption of nutrient poor staple foods. Members of mother support groups are also assisted to cultivate culturally core leafy green vegetables rich in iron and calcium such as "Alefu" (Amaranth), "Ayoyo" (Corchorus) using small scale drip irrigation systems especially during the dry season. Cooking demonstrations are also held in the communities facilitated by nutritionist and community health nurses using the mother support groups to teach soy utilization to promote improved complementary feeding, such as improved porridge for children and the preparation of diverse nutritious diets. The boiled potato chips is used to prepare "mpotompoto", a local meal as diet for the household which could also be sold to generate income for the mothers.

In-depth interviews with the monitoring and evaluation officer of the erstwhile United States Agency for International Development (USAID)/Resileince in Northern region (RING) project that was implemented in the Northern region comfirmed that from 2015 to 2017, using small plots and better farming practices to get better yields more than 17,834 acres of land was ploughed with fund assistance from the USAID channeled through the district assemblies for the cultivation of soybeans in the Northern region by these mother support groups which yielded more than 5,200 metric tons of soybeans (about 1,730 metric tons per year). While over 10,000 women were also assisted through the same source with vines to cultivate about 1,000 metric tons of orange flesh sweet 
potato. Over 3,400 women were also assisted to cultivate 2,500 acres of groundnuts adopting farming practices that prevented the growth of aflatoxins.

From the survey data from the northern region, by the end of 2017, cooking demonstrations to teach how soy and orange flesh sweet potato is utilized also benefited more than 47,300 community members in 3,300 households in over 1,200 communities. Almost 50,000 women altogether benefited from small loans because of belonging to mother-to-mother support groups in about 1,200 communities.

Nutrition-related behavior change engineered through the promotion and consumption of nutrition-sensitive agriculture nutrient-rich value chain products through community support groups would largely account for the reduction of underweight in children under 5 years especially in northern region of Ghana. Other support activities of the mother to mother support groups members such as demonstration cooking during outreach child welfare clinics and community management of under-nutrition would also partly account for the significant reduction in underweight in the northern region as shown in Fig. 5 above.

\subsection{What are the positive and negative impacts of nutrition human resource and budget expenditure on nutrition indicators?}

During routine nutrition program implementation nutrition workers promote good infant and young child feeding (IYCF) practices, including breastfeeding, and participation in community-based growth monitoring and promotion. This is essential in preventing malnutrition and improving child survival.

Nutrition programs are therefore programs that promote good infant and young child feeding and/or growth promotion programs.

The proportion of children reached by nutrition programs as shown in Fig. 7: Proportion of children 0-59 months covered by nutrition programs (2014-2017) shows an increase in the proportion of children reached with nutrition programs in at least two of the three regions (Northern and Central regions) from 2014-2017 with child welfare (CWC) coverage in the northern region being the highest while coverage in Greater Accra region was the lowest over the period which speaks volumes of the work of health workers and the work of mother support groups, as well as injection of liquidity in the Northern region nutrition activities .

The trend in coverage of children under age 5 reached with nutrition programs appear to have remained at the same level in Greater Accra region. This could partly be because of the reduction in nutrition human and financial resource in the Greater Accra region between 2014-2017 as compared with the two other regions. However, the slow increase in coverage is a pointer to the limited capacity in terms of human and financial resources with respect to the expanse of nutrition programs being implemented per region.

\section{Discussions}

This paper makes the finding of negative externalities faced by urban dwellers due to difficulty by the health workers to send information to all residents in a locality especially poor urban communities as a result of a lack of consultation with residents and inadequate logistics which contributes to a situation of low uptake of services in urban areas. This conforms to findings by(Crocker-Buque, Mindra, Duncan, \& Mounier-Jack, 2017)(World Health Organization \& UN-HABITAT, 2010) who advance the argument that, lack of awareness of the importance of health interventions and poor access to health care are among the reasons accounting for the low coverages among other factors for poor urban dwellers which could improve if the interventions are designed with their involvement

The paper makes the finding of rent-seeking behavior by members of mother support groups in urban areas who demand for incentives and payments in return for their services which conforms with similar finding by (Mercier, 2019) in her study of United States food aid programs found that, when these programs initially commenced they provided rents to implementing partners through their purchasing and shipping preferences which moved more of the program resources to producers of requested commodities, non-governmental organizations and shipping companies often raising program cost and resulting in the achievement of suboptimal program goals .Findings by (Washio et al., 2020) attest to financial incentives provided to experimental subjects in a randomized control trial in the special supplemental nutrition program for women infants and children to significantly

Page 15/27 
increase breastfeeding rates. However rate increases obtained were contingent on any level of breastfeeding rather than exclusive breastfeeding which would have been the ultimate. Findings by(Ogwang, Vanclay, \& van den Assem, 2019) provide evidence that rent-seeking behavior could even yield less than expected results. It could have undesirable social impacts including corruption and food insecurity among others

This paper makes the findings about poor targeting of under 5year old children in urban areas in nutrition programs implementation thereby missing out a potentially large cohort of chidren under age 5 with nutitional problems that could have been addressed.Findings by (Dabone C, Delisle HF, \& Receveur O., 2011) point to poor targeting as a cause for the malnutrition and micronutrient deficiencies widely prevalent in schoolchildren in cities in Burkina Faso,a neighboring country to Ghana and advocated for nutrition interventions to target chidren in cities as well .Findings by (Ruel \& Alderman, 2013) also suggest improving targeting as a way to enhance nutrition programs.

This paper makes the finding that underweight in children under 5years in the three focus regions in Ghana is declining but at a slow pace due to the limited capacity in terms of human and financial resource as well as due to the large scale of the nutrition program being implemented. This conforms with findings by (Aryeetey, 2014) who state that barriers to optimize nutrition services include limited financial resources, personnel and the need for quality service delivery This is also coherent with findings by (Frempong \& Annim, 2017) who held that the health of children in Ghana has currently seen improvement however the number of children with improved nutritional status is still below the global benchmarks.

This paper makes the findings that the amount of reduction in underweight differed from one region to the other, which could partly be attributed to the level of effort by way of deployment of resources and asserts to implement nutrition programs. This finding is upheld by (Nestel, 2000) (Mason, Sanders, Musgrove, \& Galloway, 2006) who opine that such improvements could be attributed to nutrition-sensitive interventions put in place as well as the fundamental social and health changes that have occurred in those environments. This position is also in sync with (Government of Ghana, 2013) that the level of improvement in nutritional status of childen under age of 5years will depend among others on the design and implementation of feeding interventions including changes in Social norms regarding types of foods, who should consume them and the required quantities.

The government also instituted incentive packages to encourage especially midwives and community health nurses to be posted to rural areas and peripheral health facilities $(\mathrm{MOH}, 2015)$. This assertion is confirmed by(Brenner et al., 2011) in their findings that Instituting an incentive package leads to improved child health and nutrition outcomes

This paper however makes the finding that human resource and expenditure for nutrition services although important, are not significant predictors of underweight. Other authors such as (Adhikari et al. 2017, Gödecke, Stein, and Qaim 2018) upheld this finding to the effect that although the public health system, especially growth monitoring is relevant in reducing underweight, other associated factors significantly contribute to the decline in underweight.This is contrary to findings by (Ayogu, Afiaenyi, Madukwe, \& Udenta, 2018) who argue that weekly food expenditure is a major predictor of underweight among school childen aged 6-15 years in their study to predict the prevalence of underweight among school children from poor rural communities in South-eastern Nigeria. This study however, focuses on underweight for children 0-5years which was not the focus age group of Ayogu et al. 2018 however they advocated the need for an effective community-based interventions among others.

This paper finds that other associated factors such as nutrition education and behavior change activities implemented through mother support groups significantly influenced underweight which is in sync with (Chowdhury et al. 2018, Tette, Sifah, and Nartey 2015, Alasfoor et al. 2007) in their submission that, other socio-economic factors including mother's education level ,care for the child, monthly family income as well as environmental sanitation which results in behavioral change, is significantly associated with reduction in underweight even after hugh improvements in health services .

Mother support groups are characteristed by (Hockstein, 2011) as groups where, members Share breastfeeding and complementary feeding information as well as their personal experiences as mothers as they learn from each other which help reinforce or change certain attitudes and practices of these mothers. The women also support each other as they care for their under 5year old children. 
This paper's assertion that the mother support groups are more effective and sustainable in rural settings where there is stronger social bonding and shorter distances to meeing places than urban settings is supported by findngs by (Hockstein, 2011) who also opined that mother support groups thrive on existing community groups with meeting times not interfering with activities of the members including market days, while meeting place should be a short distance away within the community, a description which better explains rural setting within the African context.

This paper again found that the cultivation and consumption of soybeans and Orange-Fleshed Sweet Potatoes was used as a strategy to manage problems of malnutrion in the communities which is supported by findings made by (Julianti, Rusmarilin, Ridwansyah, \& Yusraini, 2017) to the effect that the high nutritional value of Orange-Fleshed Sweet Potatoes and soyabean makes their consumption suitable in the management of malnutrition problems, a view shared by(Adetola, Onabanjo, \& Stark, 2020) who also add that consumption of soybeans and Orange-Fleshed Sweet Potatoes is useful for purposes of supplementary foods for infants.

This paper makes the findings of cooking demonstrations by mother support groups to teach how soy and orange flesh sweet potato is utilized which engineered nutrition-related behavior change among the community people which positively impacted undernutrition levels among children under 5-years especially in the northern region. This is in sync with earlier findings by(FAO, 2005) from the integrated nutrition-agriculture intervention in Burundi where women brought their children to the nutrition rehabilitation facilities and were provided with basic training that integrates agriculture assistance, nutrition rehabilitation and nutrition education in vegetable and soybean production including cooking demonstrations in infant and child feeding knowledge and practices. This resulted in decreased incidence of malnutrition of the children attending these facilities. They advocated for the protection and improvement of approaches that contribute towards nutritional wellbeing .

This study made a finding on the impact of community women support groups in fostering behavioral change to impact undernutrition through the cultivation and consumption of nutrition-sensitive agriculture value chain products. The first part of the finding on nutrition improvement through women support groups conforms to findings by(Undlien, Viervoll, \& Rostad, 2016), (Muruka \& Ekisa, 2013) (Tobe, Islam, Yoshimura, \& Hossain, 2019) in the use of trained community support groups including women groups to improve nutritional status of children and health seeking behavior of pregnant women,. similar findings were also made by (SUN Movement, 2014), on the use of the community level Social mobilization, advocacy and communications strategy by SUN countries to empower individuals to take action to improve nutrition however no specific findings on the role played by mother support groups in reducing undernutrition in children under 5years through galvanizing communities to cultivate and consume nutrition-sensitive agriculture value chain products has been made by any researcher so far which makes it a novelty in subsarahan Africa

With the advent of the corona virus pandermic, health and nutrition services have been disrupted and in the case of inadequate care, childhood illnesses will increase along with an increase in the incidence of malnutrition(newindianexpress.com, 2020) .However the full extent of the devastation that covid-19 has caused with respect to the incidence of malnutrition is not fully known (FAO, 2020).

According to the finding of this paper, despite efforts, Ghana made at fiscal consolidation, less than expected revenue (including grants) could be mobilized espercially in 2017. According to fiindings made by (The World Bank, 2018) there were, expenditure cuts on recurrent and capital expenditures. This is against the backdrop of Ghana attaining lower middle-income status in 2010(GSS, 2011). Findings by the (International Monetary Fund, 2016) in their review under the extended credit facility arrangement stated that Ghana's lower middle income status has reduced the amount of donor funding available to the country however the government was expected to put measures in place to avoid the risk of payment delaysFinding by (Ecker, 2014) makes the case that the limited financial resources allocated to implement nutrition programs in Ghana was identified as among the myrid of reasons for the inability to adequately address malnutrition.

The finding of this paper that nutrition interventions are carried out typically at the static health facilities and during community outreach programs. This is in sync with findings by (Mason et al., 2006) who argue that such community based programs are even instrumental in promoting social demand for services. They go on to say that these community programs could be an important contributory factor to the fast improvement in health and nutrition especially in developing countries 


\subsection{Conclusions}

There are externalities in the implementation of nutrition programs for children under 5years because of poor targeting and information asymmetries in urban areas, resulting in excludability in consumption of nutrition services by urban dwellers, indicating that nutrition programs may not be well-coordinated, and implemented in urban settings and this is tantamount to Government failure.

Rent-seeking behaviour by social support groups in urban settings is associated with nutrition program implementation. On the other hand volunteerism which forms the basis for community services is gradually going down especially in urban areas in Ghana which has the potential of impacting underweight in children under 5years in the long run

The proportion of children reached with nutrition programs is increasing but at a gradual pace due to the limited capacity in terms of human and financial resource as well as due to the large scale of the program being implemented .

There is a study decline in underweight in children under 5years in the study regions. Maintaining the right balance between human resource and expenditure on nutrition contributes to achieving success in implementing nutrition programs, however human resource and expenditure for program implementation alone are not significant predictors of underweight in children under $5 y e a r s$.

Community governance through community support groups in leveraging human capital, organizational resources and social capital to solve shared problems is vital in promoting adherence to nutrition regimen. Therefore, improving community governance systems is likely to build community ownership of nutrition activities which is associated with improvement in nutritional status of children under 5 years in resource challenged settings. This is critical knowing that the total amount of resources, financial and human expended by the state for implementing nutrition programs has decreased. This is against the backdrop of dwindling donor inflows for nutrition programs that are largely donor-driven and this has affected funding for nutrition related activities.

Related to that is the achievement of nutrition related behavior change through the promotion and consumption of nutritionsensitive agriculture nutrient-rich value chain products which are vital in engineering a reduction in underweight in children under 5years .

Social innovations through community demonstration cooking and small farms in the community, helps foster socialization, which is a positive externality for communities and a catalyst in reducing underweight for children under 5 years old.

Therefore the allocation of resources, both human and material, for nutrition program implementation alone without adequate governance structures by both state and community actors within the socio-cultural context will not result in adequate care and feeding practices that is required to change the prevalence of underweight in children under 5years

\section{Declarations}

\section{Ethics approval and consent to participate}

Secondary cross-sectional data on anthropometric measurements of weight and age with no unique identifiers was used in this study so there was no direct measurement of underweight. Health providers views was sought on their role as health workers in nutrition program implementation and not as individuals in their private capacity.

There are no physical risks associated with the study. However, there is a potential social risk due to the invasion of the privacy of the subjects enrolled in the in-depth interviews . Enough education was given to the subjects to minimize the social risk associated with the invasion of their privacy. There are also no immediate benefits to participants, but long-term benefits could result from the study in terms of the adoption of efficient approaches in mitigating the effects of governance challenges in nutrition program implementation which may improve nutritional status of beneficiaries in the long run.

All data collected through quantitative and qualitative methods and recordings of the discussions will be kept confidential and was used only for the purposes of the research. 
Participation in the study was voluntary and one was not obliged to participate. One was free to withdraw from the study at any point during the study without any penalty. No compensation was due any person who participated in the study.

At the community, facility and institutional levels, entry protocols was followed, and permission was sought from the respondents directly and also through their heads of institutions or in case of community, from assembly men and opinion leaders before interviews were conducted. Participants who for good reasons could not sign the consent form was asked to thumbprint against their names.

\section{Availability of data and materials}

The datasets generated during and/or analysed during the current study are not publicly available due to the fact the online Ghana Health Service data repository contains client personal records and other sensitive health information of patients and is not available for public use and is password protected but are available from the corresponding author on reasonable request

\section{Competing interests}

The authors declare that they have no competing interests

\section{Funding}

The Research was funded by the Food Security Center (FSC) of the University of Hohenheim, Wollgrasweg 43 D-70593 Stuttgart Germany. This consisted of funding the entire data collection exercise which included paying for accommodation and meals for the researcher and research assistant as well as transportation and logistics

\section{Authors' contributions}

GW collected analyzed and interpreted the patient data regarding the anthropmetric data on children under age 5 and in-depth interviews. RB contributed the methodology and method of analysis ey, and was a major contributor in determining th scope of the manuscript. All authors read and approved the final manuscript

\section{Acknowledgments}

The Research was undertaken under the auspices of :

Food Security Center (FSC)

University of Hohenheim , Wollgrasweg 43

D-70593 Stuttgart Germany

\section{References}

1. Adano U, O'Neil M, Browne CF, Fox J. (2012). Human resources management and capacity development. Managing Access to Medicines and Health Technologies, 51.2-51.28. Retrieved from

http://apps.who.int/medicinedocs/documents/s19628en/s19628en.pdf.

2. Adetola OY, Onabanjo 0O, Stark AH. (2020). The search for sustainable solutions: Producing a sweet potato based complementary food rich in vitamin A, zinc and iron for infants in developing countries. Scientific African, 8. https://doi.org/10.1016/j.sciaf.2020.e00363.

3. Adhikari D, Khatri RB, Paudel YR, Poudyal AK. Factors Associated with Underweight among Under-Five Children in Eastern Nepal: Community-Based Cross-sectional Study. Frontiers in Public Health. 2017;5(December):1-9.

Page $19 / 27$ 
https://doi.org/10.3389/fpubh.2017.00350.

4. Alasfoor D, Traissac P, Gartner A, Delpeuch F. Determinants of persistent underweight among children, aged 6-35 months, after huge economic development and improvements in health services in Oman. Journal of Health Population Nutrition.

2007;25(3):359-69. https://doi.org/10.3329/jhpn.v25i3.645.

5. Aryeetey R. (2014). IMPLEMENTING NUTRITION INTERVENTIONS IN GHANA AT DISTRICT LEVEL: GAPS AND OPPORTUNITIES. IMPLEMENTING NUTRITION INTERVENTIONS IN GHANA AT DISTRICT LEVEL : GAPS AND OPPORTUNITIES Gongwer CR 1 and $R$ Aryeetey 1 * Cameron R. Gongwer School of Public Health. (April).

6. Ayogu RNB, Afiaenyi IC, Madukwe EU, Udenta EA. Prevalence and predictors of under-nutrition among school children in a rural South-eastern Nigerian community: A cross sectional study. BMC Public Health. 2018;18(1):1-9. https://doi.org/10.1186/s12889-018-5479-5.

7. Brenner JL, Kabakyenga J, Kyomuhangi T, Wotton KA, Pim C, Ntaro M, ... Singhal N. (2011). Can Volunteer Community Health Workers Decrease Child Morbidity and Mortality in Southwestern Uganda ? An Impact Evaluation. 6(12). https://doi.org/10.1371/journal.pone.0027997.

8. Britto PR, Yoshikawa H, Ravens J, Van, Ponguta LA, Reyes M, Oh S, ... Seder R. (2014). Strengthening systems for integrated early childhood development services: a cross-national analysis of governance. 245-255. https://doi.org/10.1111/nyas.12365.

9. Brunet M, Aubry M. The three dimensions of a governance framework for major public projects. Int J Project Manage. 2016;34(8):1596-607. https://doi.org/10.1016/j.ijproman.2016.09.004.

10. Chowdhury TR, Chakrabarty S, Rakib M, Saltmarsh S, Davis KA. Socio-economic risk factors for early childhood underweight in Bangladesh. Globalization Health. 2018;14(1):1-12. https://doi.org/10.1186/s12992-018-0372-7.

11. Coster G, De. (2014). Introduction to Linear Mixed Models. (Ahm 3), 1-48. Retrieved from https://stats.idre.ucla.edu/other/mult-pkg/introduction-to-linear-mixed-models/.

12. Crigler L, Gergen J, Perry H. (2013). Supervision of Community Health Workers. Washington, DC: USAID/Maternal and Child, (September), 1-26. Retrieved from http://www.mchip.net/sites/default/files/mchipfiles/09_CHW_Supervision.pdf.

13. Crocker-Buque T, Mindra G, Duncan R, Mounier-Jack S. Immunization, urbanization and slums - A systematic review of factors and interventions. BMC Public Health. 2017;17(1):1-16. https://doi.org/10.1186/s12889-017-4473-7.

14. Cudjoe SN, Azure T, Assem C, Nortey EN. (2013). 2010 Population \& Housing Census Northern Regional Analytic Report. 1135.

15. Dabone C, Delisle HF, Receveur O. (2011). Poor nutritional status of schoolchildren in urban and peri-urban areas of Ouagadougou (Burkina Faso). Nutrition Journal, 1-8. Retrieved from http://www.nutritionj.com/content/10/1/34\%0ARESEARCH.

16. de Onis M;et al. WHO Child Growth Standards based on length/height, weight and age. Acta Paediatrica (Oslo Norway: 1992) Supplement. 2006;450:76-85.

17. Dupas P. (2018). The Role of Cash Transfer in Improving Child Health: A Review of the Evidence. (August). Retrieved from https://www.povertyactionlab.org/sites/default/files/documents/Cash Transfers Review Paper_2018.10.09.pdf.

18. Ecker O. (2014). Nutrition Policies in Developing Countries: Challenges and Highlights. (October 2012). Retrieved from esearchgate.net/publication/266374535_Nutrition_Policies_in_Developing_Countries_Challenges_and_Highlights.

19. FAO. The State of Food Security and Nutrition in the World 2020. Transforming food systems for affordable healthy diets. IEEE Journal of Selected Topics in Applied Earth Observations Remote Sensing. 2020. https://doi.org/https://doi.org/10.4060/ca9692en.

20. FAO F and A. O. (2005). Protecting and promoting good nutrition in crisis and recovery. Retrieved from http://www.unscn.org/layout/modules/resources/files/Refman_36_FAO_Protecting_and_promoting_Good_Nutrition_in_Cri.pdf.

21. Frempong RB, Annim SK. Dietary diversity and child malnutrition in Ghana. Heliyon. 2017;3(5):e00298. https://doi.org/10.1016/j.heliyon.2017.e00298.

22. Ghana Statistical Service. (2015). Ghana Demographic Health Survey. Retrieved from https://dhsprogram.com/pubs/pdf/FR307/FR307.pdf. 
23. Ghana Statistical Service. (2019). Ghana Multiple Indicator Cluster Surveys Snapshots of key findings. Retrieved from https://www.unicef.org/about/annualreport/files/Ghana-2019-COAR.pd.

24. Glover-amengor M, Agbemafle I, Hagan LL, Mboom FP, Gamor G. (2016). Nutritional status of children 0-59 months in selected intervention communities in northern Ghana from the africa RISING project in 2012. Archives of Public Health, 1-12. https://doi.org/10.1186/s13690-016-0124-1.

25. Gödecke T, Stein AJ, Qaim M. (2018). The global burden of chronic and hidden hunger: Trends and determinants. Global Food Security, 17(December 2017), 21-29. https://doi.org/10.1016/j.gfs.2018.03.004.

26. Government of Ghana. (2013). National Nutrition Policy 2014-2017. (September 2013), 3-46. Retrieved from http://extwprlegs1.fao.org/docs/pdf/gha145267.pdf.

27. GSS GSS. (2011). National Income 2010. 2010(August). Retrieved from http://www.statsghana.gov.gh/docfiles/GDP/national_income_2010.pdf.

28. Hockstein E. (2011). Mother-to-Mother Support Groups. (March). Retrieved from http://www.iycn.org/files/IYCN_Mother-toMother-Support-Group-Facilitator-Manual_0311.pdf.

29. International Food Policy Research Institute (IFPRI). (2015). Scaling up financial and capacity resources for nutrition. Global Nutrition Report 2015: Actions and Accountability to Advance Nutrition and Sustainable Development, 58-74. Retrieved from http://ebrary.ifpri.org/utils/getfile/collection/p15738coll2/id/129449/filename/129660.pdf.

30. International Monetary Fund. (2016). GHANA SECOND REVIEW UNDER THE EXTENDED CREDIT FACILITY ARRANGEMENT AND REQUEST FOR WAIVER FOR NONOBSERVANCE OF PERFORMANCE CRITERION. Retrieved from https://www.imf.org/external/pubs/ft/scr/2016/cr1616.pdf.

31. ISD. (2017). GHANA REGIONS. Information Services Department,Ghana. Retrieved from info.isd@isd.gov.gh.

32. Johnston M. (2016). Good Governance: Rule of Law, Transparency, and Accountability. (April), 1-32. Retrieved from http://unpan1.un.org/intradoc/groups/public/documents/un/unpan010193.pdf.

33. Julianti E, Rusmarilin H, Ridwansyah, \& Yusraini E. Functional and rheological properties of composite flour from sweet potato, maize, soybean and xanthan gum. Journal of the Saudi Society of Agricultural Sciences. 2017;16(2):171-7. https://doi.org/10.1016/j.jssas.2015.05.005.

34. Kampman H, Zongrone A, Rawat R, Becquey E. (2016). How Senegal created an enabling environment for nutrition: A story of change. Global Food Security, 13(October 2016), 57-65. https://doi.org/10.1016/j.gfs.2017.02.005.

35. Mason JB, Sanders D, Musgrove P, Galloway R. (2006). Chapter 56. Community Health and Nutrition Programs. Disease Control Priorities in Developing Countries (2nd Edition) The International Bank for Reconstruction and Development / The World Bank; 2006. Chapter 56. Available From:, 1053-1074. https://doi.org/10.1596/978-0-8213-6179-5/chpt-56.

36. Mercier S. (2019). Rent-Seeking-in-Food-Aid.pdf. Retrieved from https://www.aei.org/wp-content/uploads/2019/01/RentSeeking-in-Food-Aid.pdf.

37. Ministry of Health [Ethiopia]. (2014). HMIS Indicator Definitions- Technical Standards: Area 1. 13-14. Retrieved from https://www.measureevaluation.org/our-work/routine-health-information-systems/rhis-curriculum-modules/handout-2-2.4b.

38. MOH M of H. (2015). Under 5 Child Health Strategy: 2007-2015. 2007-2015. Retrieved from ttps://extranet.who.int/nutrition/gina/en/node/23184.

39. Mucha N, Tharaney M. (2013). Strengthening Human Capacity to Scale Up Nutrition. (June), 10-11. Retrieved from http://www.fao.org/fsnforum/sites/default/files/discussions/contributions/strengthening-human-capacityFINAL_June_2013.pdf.

40. Muruka C, Ekisa H. A Case Study on the Impact of Mother-to-Mother Support Groups on Maternal, Infant and Young Child Nutrition and Care Practices in Habaswein and Wajir South Districts of North Eastern Kenya. Food Nutrition Sciences. 2013;04(10):31-5. https://doi.org/10.4236/fns.2013.410a006.

41. Nestel P. (2000). Strategies, Policies and Programs to Improve the Nutrition of Women and Girls. (January). Retrieved from https://reliefweb.int/sites/reliefweb.int/files/resources/7C9F28EA4186E26AC1257410003A3D48-fanta_jan2000.pdf.

42. newindianexpress.com. (2020). Malnutrition among children: The unspoken side of COVID-19 pandemic- The New Indian Express. Retrieved July 15, 2020, from https://www.newindianexpress.com/cities/delhi/2020/jun/29/malnutrition-amongchildren-the-unspoken-side-of-covid-19-pandemic-2162806.html.

Page 21/27 
43. Newson RS, Lion R, Crawford RJ, Curtis V, Elmadfa I, Feunekes GIJ, ... Uauy R. (2013). Behaviour change for better health: Nutrition, hygiene and sustainability. BMC Public Health, 13(SUPPL. 1), 1-13. https://doi.org/10.1186/1471-2458-13-S1-S1.

44. OECD. (2014). The role of accountability in promoting good governance. Accountability and Democratic Governance: Orientations and Principles for Development, 19-31. https://doi.org/http://dx.doi.org/10.1787/9789264183636-4-en.

45. Ogwang T, Vanclay F, van den Assem A. (2019). Rent-seeking practices, local resource curse, and social conflict in Uganda's emerging oil economy. Land, 8(4). https://doi.org/10.3390/land8040053.

46. Pereira D, Greenfield D, Ranmuthugala G, Braithwaite J. (2013). The role and potential of Human Resources departments in healthcare organisations. 1-4. Retrieved from https://isqua.org/docs/edinburgh-powerpoint-presentations-2013/1045-b1-dgreenfield-ochil-tues-the-role-and-potential-of-human-resources-departments-in-healtcare-organisation.pdf?sfvrsn=2.

47. Picanyol C. (2014). Financial Resource Tracking for Nutrition: Current State of the Art and Recommendations for Moving Forward. 1-3. Retrieved from http://scalingupnutrition.org/wp-content/uploads/2013/02/140120-Tracking-Investments-onNutrition.pdf.

48. Rose J, Mostafa S, Robbins K. (2014). Nutrition Governance in Bangladesh.

49. Ruel MT, Alderman H. Nutrition-sensitive interventions and programmes: How can they help to accelerate progress in improving maternal and child nutrition? The Lancet. 2013;382(9891):536-51. https://doi.org/10.1016/S0140-6736(13)60843-0.

50. Savage JD. (2013). Iraq's Budget as a Source of Political Stability. United States Institute of Peac. Retrieved from https://www.usip.org/sites/default/files/SR328-Iraqs Budget as a Source of Political Stability.pdf.

51. SUN Movement. (2014). Social Mobilisation, Advocacy and Communication for Nutrition. Scaling Up Nutrition, (July). Retrieved from https://scalingupnutrition.org/wpcontent/uploads/2014/09/Green_External_InPractice_no03_ENG_20140904_web_pages.pdf.

52. Susan H, et al. (2010). Scaling Up Nutrition - What Will It Cost? Retrieved from http://siteresources.worldbank.org/HEALTHNUTRITIONANDPOPULATION/Resources/Peer-ReviewedPublications/ScalingUpNutrition.pdf.

53. Swaminathan MS. Zero hunger. Science. 2014;345(6196):491. https://doi.org/10.1126/science.1258820.

54. Tette EMA, Sifah EK, Nartey ET. Factors affecting malnutrition in children and the uptake of interventions to prevent the condition. BMC Pediatrics. 2015;15(1):1-11. https://doi.org/10.1186/s12887-015-0496-3.

55. The World Bank, W. (2018). Ghana Overview. Retrieved from http://www.worldbank.org/en/country/ghana/overview.

56. Thomas F. Six Components Necessary for Effective Public Health Program Implementation. American Journal Of Public Health. 2014;104(1):17-23. https://doi.org/10.2105/AJPH.2013.301608.

57. Thrall GI. Public goods and externalities. Land Use Urban Form. 2018;80:174-96. https://doi.org/10.4324/9781315165721-13.

58. Tobe RG, Islam MT, Yoshimura Y, Hossain. Strengthening the community support group to improve maternal and neonatal health seeking behaviors: A cluster-randomized controlled trial in Satkhira District, Bangladesh. PLoS ONE. 2019;14(2):1-19. https://doi.org/10.1371/JOURNAL.PONE.0212847.

59. UN UN. (2017). World Population Prospects: The 2017 Revision Total population (both sexes combined) by region, subregion and country, annually for 1950-2100 (thousands) Estimates, 1950-2015. 2100(June 2017), 5-6. Retrieved from https://esa.un.org/unpd/wpp/Download/Standard/Population/.

60. Undlien M, Viervoll H-A, Rostad B. (2016). Effect of mother support groups on nutritional status. 4. Retrieved from https://africanhealthsciences.org/2017/10/11/effect-of-mother-support-groups-on-nutritional-status/.

61. Warren AM, Frongillo EA. Mid-level actors and their operating environments for implementing nutrition-sensitive programming in Ethiopia. Global Food Security. 2016. https://doi.org/10.1016/j.gfs.2017.01.010.

62. Washio Y, Collins BN, Hunt-Johnson A, Zhang Z, Herrine G, Hoffman M, ... Furman LM. Individual breastfeeding support with contingent incentives for low-income mothers in the USA: The "BOOST (Breastfeeding Onset \& Onward with Support Tools)" randomised controlled trial protocol. BMJ Open. 2020;10(6):1-8. https://doi.org/10.1136/bmjopen-2019-034510.

63. WHO (World Health Organization). (2016). Chapter 14: Migration and retention of health care workers. 216-225. Retrieved from https://www.who.int/healthsystems/topics/health-law/chapter14.pdf. 
64. World Health Organization. (2017). Accelerating nutrition improvements in Sub-Saharan Africa: scaling up nutrition interventions. Final report 2012-2016. Retrieved from http://apps.who.int/iris/bitstream/10665/255422/1/WHO-NMH-NHD17.6-eng.pdf.

65. Organization WH, W., \& UN-HABITAT. Unmasking and Overcoming Health Inequities in Urban Settings. Evol Ecol. 2010;10:1145.

66. World P-, Fanzo JC, Graziose MM, Kraemer K, Gillespie S, Johnston JL, ... Pepping F. Educating and Training a Workforce for Nutrition. Advances in Nutrition. 2015;6(NOVEMBER):639-47. https://doi.org/10.3945/an.115.010041.(4).

67. Zureiqat G, Shama HA. (2015). Social Protection and Safety Nets in Jordan. (December). Retrieved from http://www.ids.ac.uk/publication/social-pro-.

\section{Figures}

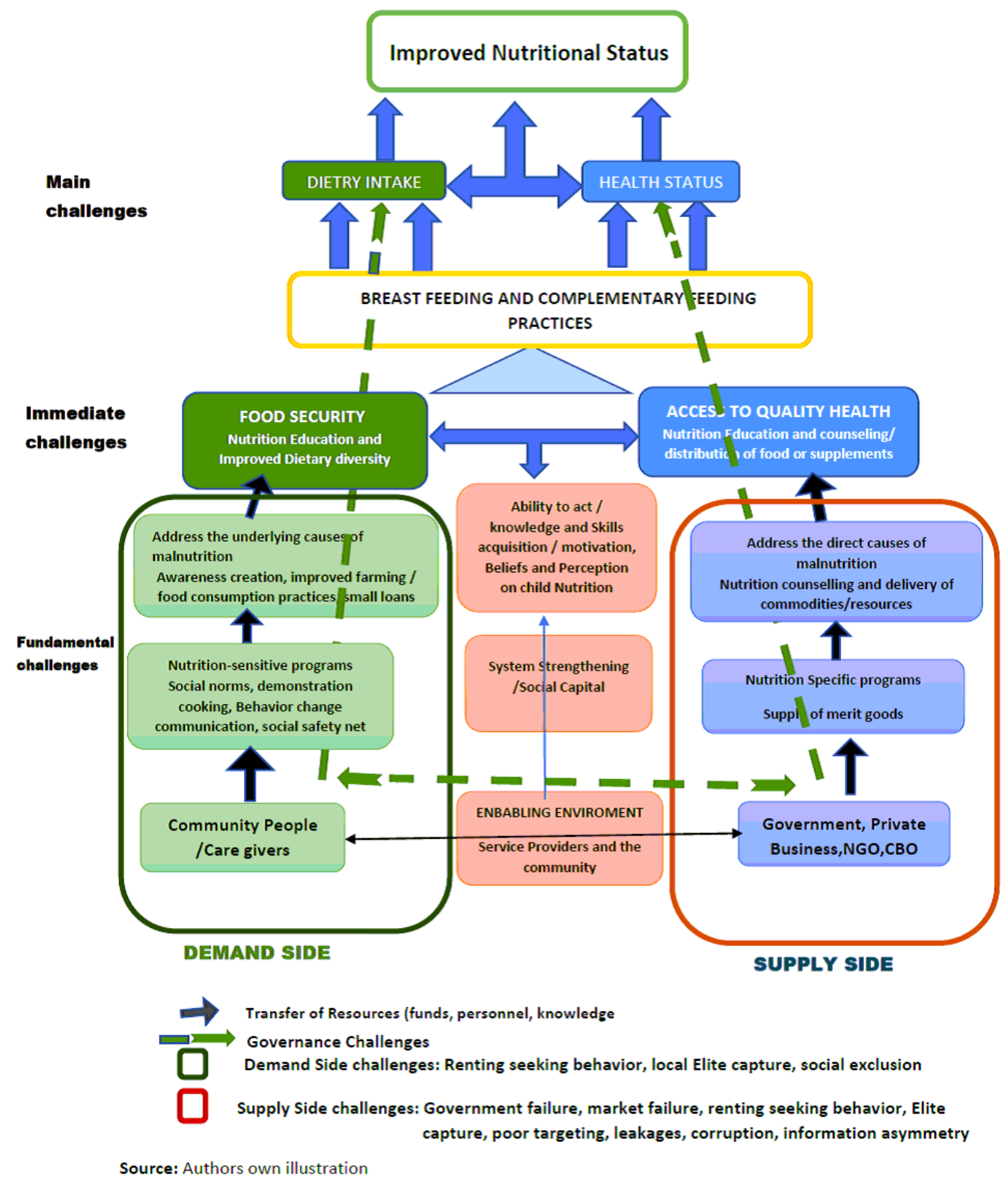

Figure 1

Conceptual Framework 


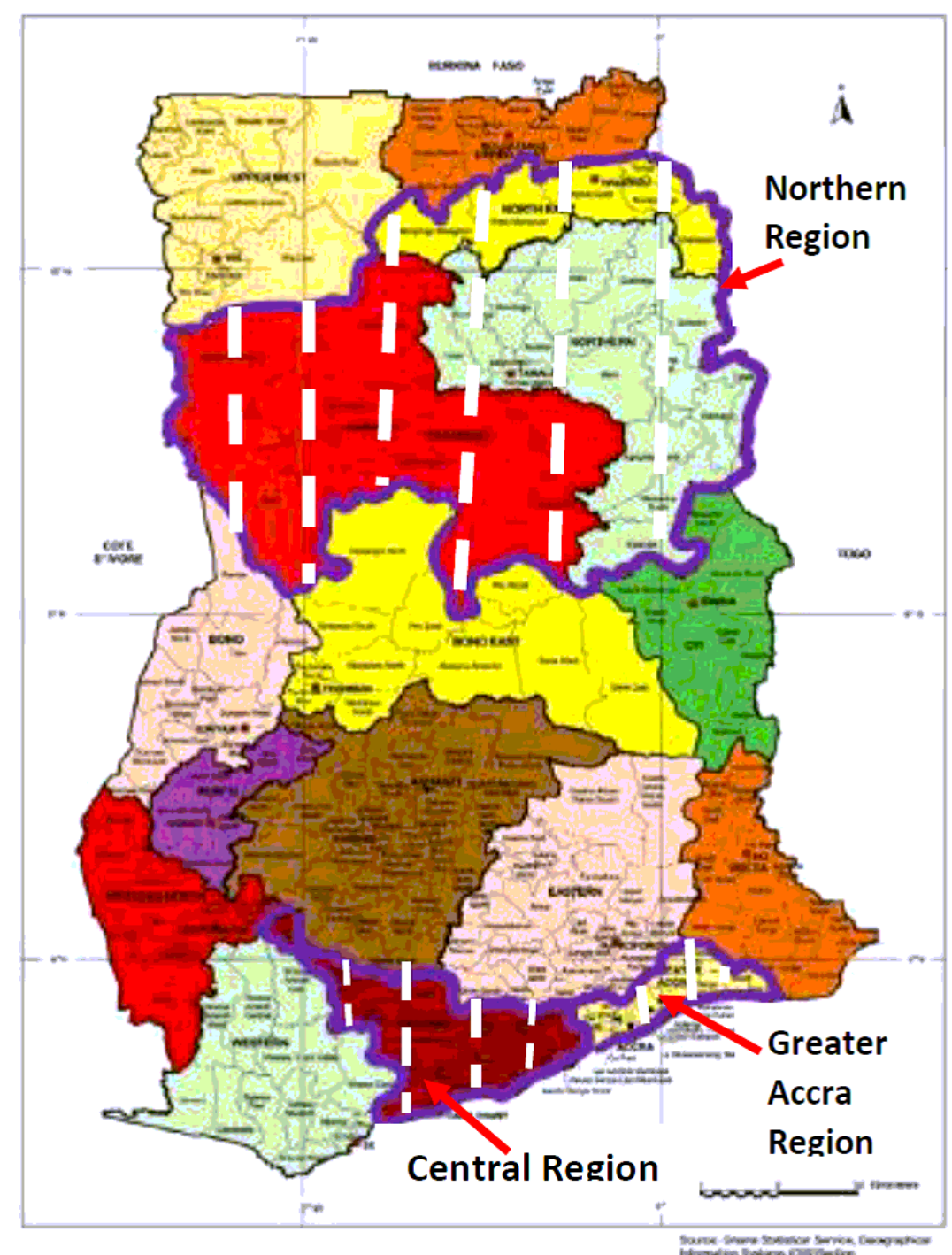

Source : own illustration based on (Ghana Statistical Service 2019)

Figure 2

The Selected Regions of Ghana 


\section{EXPENDITUE FOR NUTRITION PROGRAMS (2014 -}

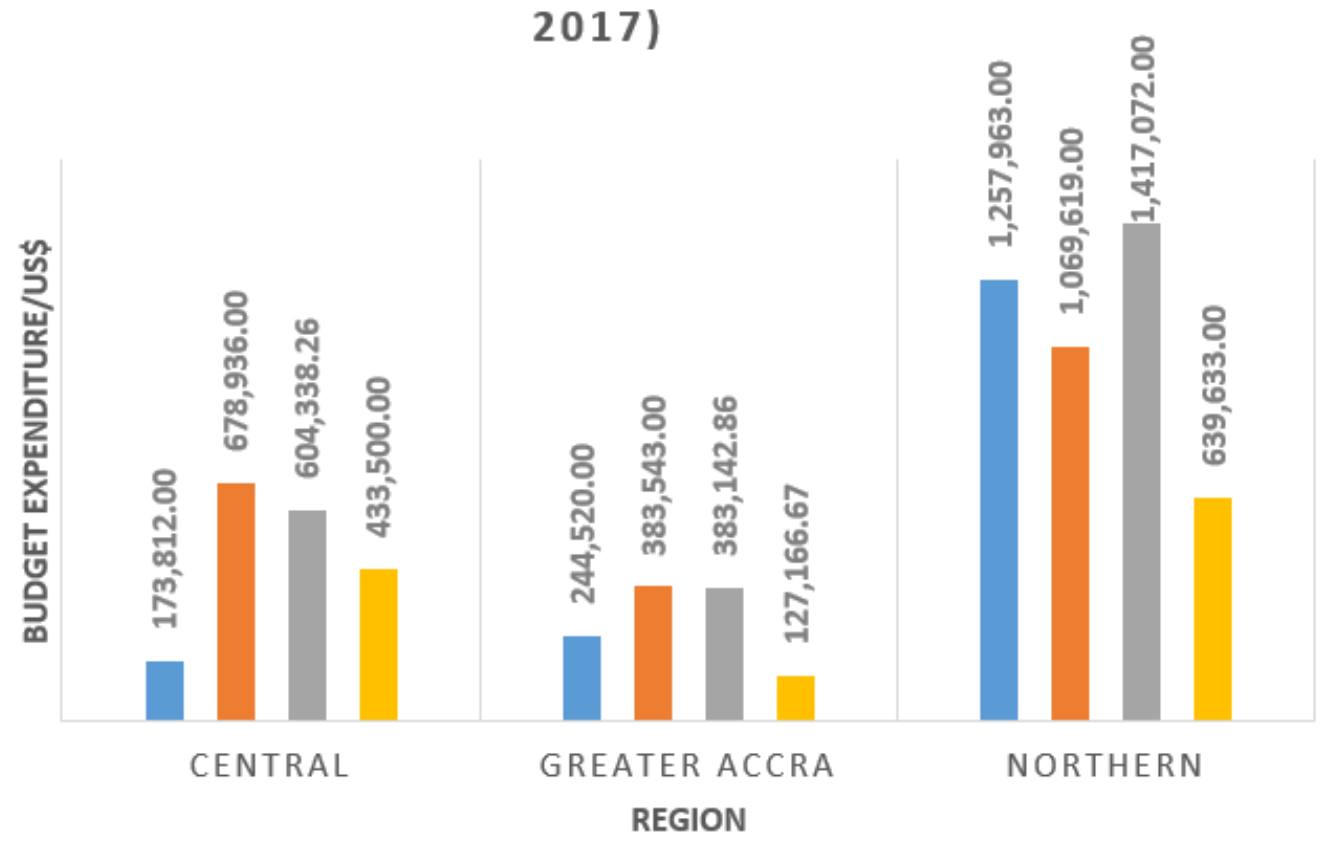

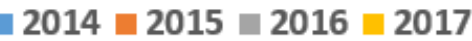

\section{Figure 3}

Estimated expenditure on nutrition programs in the three regions ,2014 - 2017 Source: Own Illustration based on data from UNICEFGhana and Ghana Health Service Performance review meetings

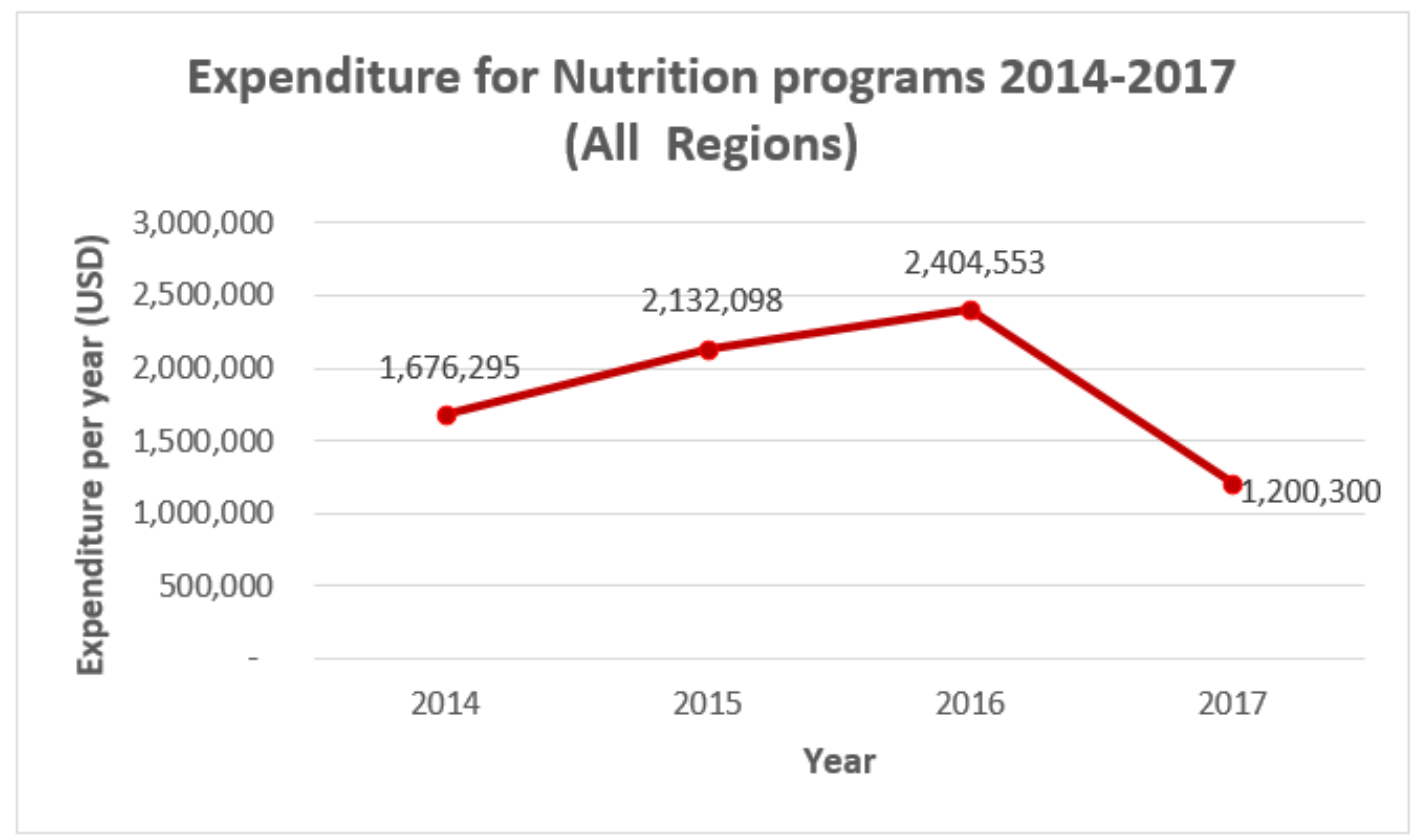

\section{Figure 4}

Trends in Total Expenditure for Nutrition program in all three regions (2014-2017) Source: Own illustration based on data from UNICEF-Ghana 2018 


\section{Proportion of Children Underweight In All Districts of Three Study Regions in Ghana (2014-2017)}

$25 \%$

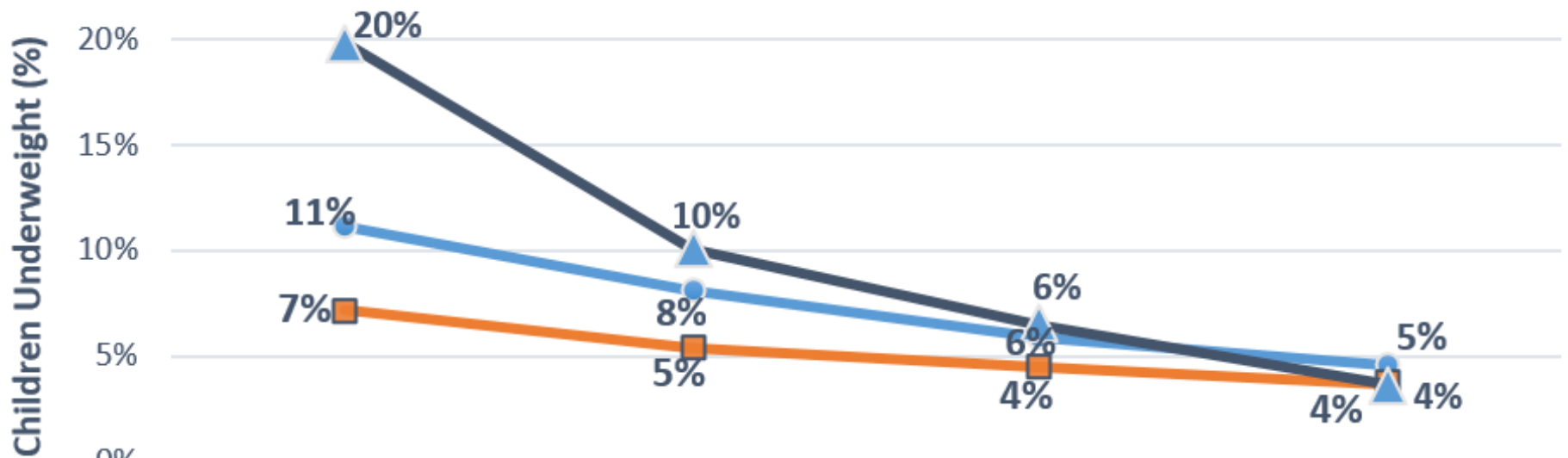

$0 \%$

$2014 \mathrm{~N}=1,882,9792015 \mathrm{~N}=3,672,747 \quad 2016 \mathrm{~N}=4,554,748 \quad 2017 \mathrm{~N}=3,418,260$

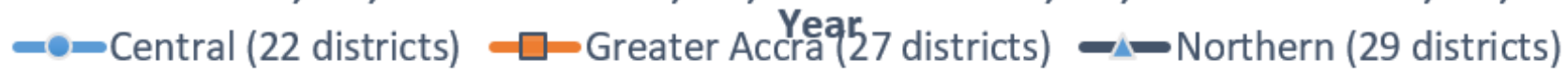

\section{Figure 5}

Children Underweight as an Outcome of Nutrition Program Implementation (2014-2017) Source: Own illustration based on Ghana Health Service Annual Performance review meetings data (2015-2018)

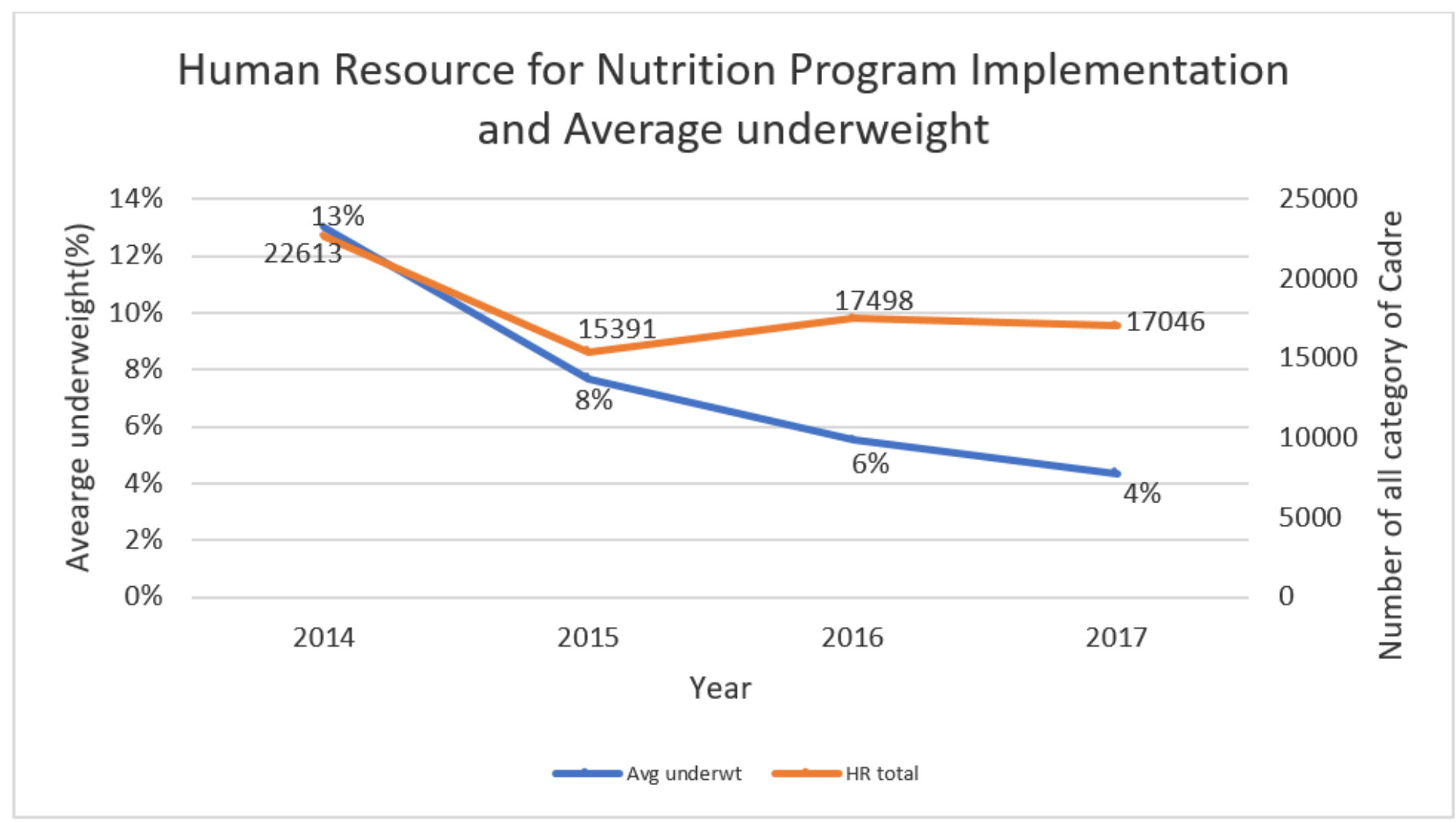

Figure 6 
Human Resource for Nutrition programs and Average underweight in All Regions (2014 - 2017) Source: Own illustration based on data from Ghana Health Service Annual Performance review meetings

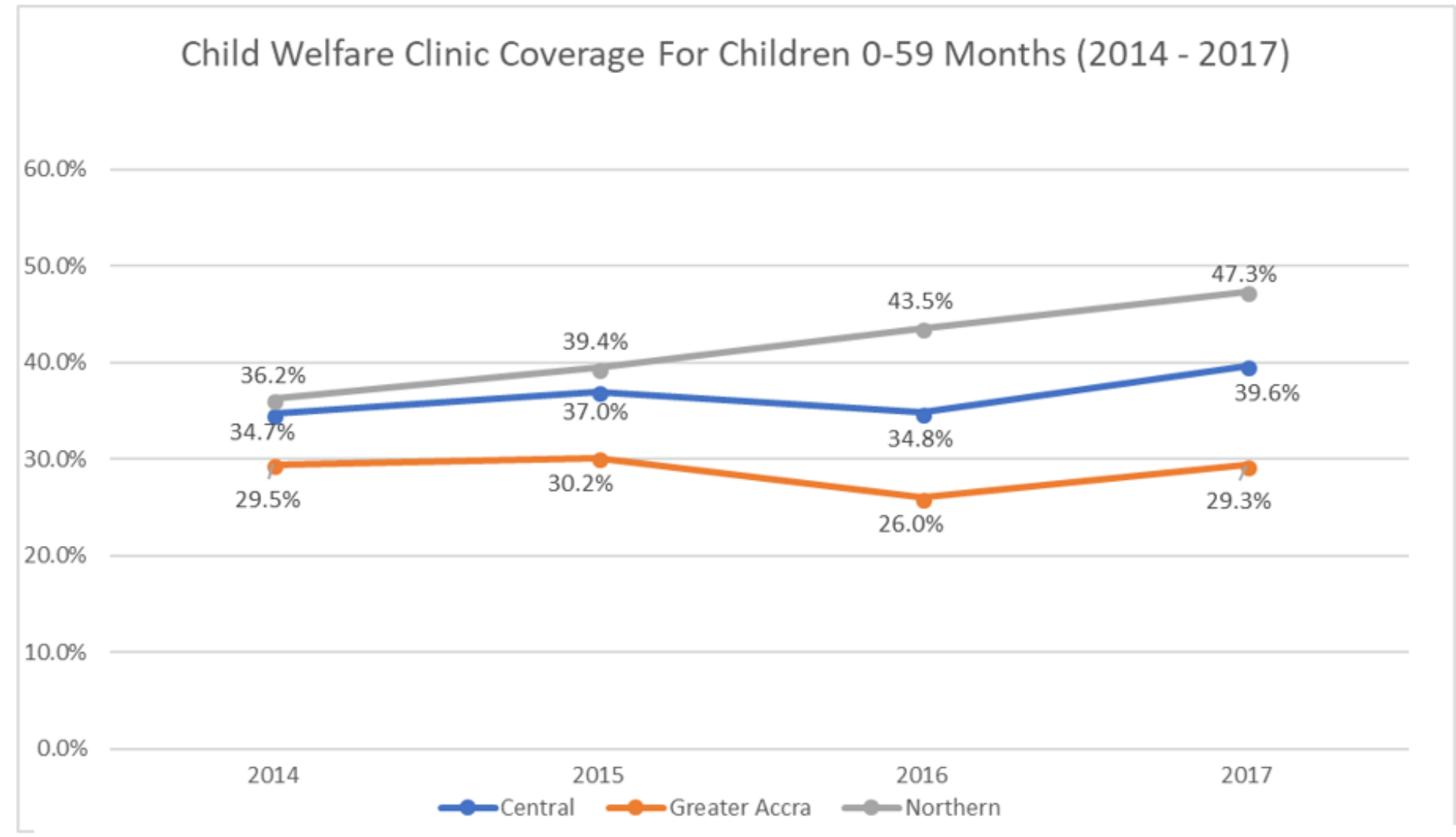

\section{Figure 7}

Proportion of children 0-59 months covered by nutrition programs (2014-2017) Source: Own illustration based on data from Ghana Health Service Annual Performance review 